\title{
Efectos del crecimiento urbano sobre humedales costero-continentales del ambiente semiárido de Tierra del Fuego, Argentina
}

\author{
Effects of urban growth on coastal and continental wetlands \\ in the semiarid environment of Tierra del Fuego, Argentina
}

\author{
Rodolfo Javier Iturraspe $\mathrm{1}^{1^{*}}$ (iD) \\ Lucía Fank ${ }^{2}$ \\ Adriana Beatriz Urciuolo ${ }^{3}$ \\ Rita Lofiego ${ }^{4}$ (D)
}

\section{Resumen}

La conjunción de humedales costeros y continentales en zonas semiáridas y en adyacencias urbanas, representa un valioso patrimonio socio-ambiental, sujeto a las tensiones que la expansión urbana genera, especialmente si se manifiesta con altas tasas de crecimiento. El presente artículo aborda el problema de los cambios físicos sobre humedales provocados por la expansión urbana acelerada en el contexto mencionado, identificando factores agravantes. Se estudió el caso de Río Grande, ciudad costera de la estepa de Tierra del Fuego, Argentina, cuyo crecimiento fue impulsado desde 1972 por políticas de promoción industrial. Los humedales fueron identificados, clasificados y cartografiados mediante análisis multiespectral de imágenes de satélite. La expansión urbana se delimitó según tres períodos vinculados a variantes en las políticas de promoción. El análisis espacio-temporal evidencia correspondencia entre pulsos de fluctuación de las políticas, con la dinámica de la expansión urbana y ocupación de áreas naturales. Un tercio de la expansión urbana fue a expensas de la desaparición de humedales, con saldo adicional de unidades fragmentadas. Se analizan externalidades, no siempre evidentes, resultantes de la urbanización de estos ecosistemas y se concluye en la significación de los asentamientos informales, así como la falta de planificación como factores que incrementan la pérdida de humedales.

Palabras clave: humedales; expansión urbana; Río Grande; Tierra del Fuego; costas; estuarios; vegas.

\begin{abstract}
Coastal and continental wetlands in semi-arid environments near urban areas denote a valuable socioenvironmental heritage. These areas are exposed to stresses generated by urban expansion, especially if that expansion is rapid. This paper focuses on the physical changes in wetlands caused by such urban expansion and on the factors that increase this problem. The study case is focused on the city of Río Grande. This coastal city is on the steppe of Tierra del Fuego, Argentina, and its expansion started in 1972 following industrial promotion policies. Wetland identification, classification, and mapping from the multispectral

1 Instituto de Ciencias Polares, Ambiente y Recursos Naturales, Universidad Nacional de Tierra del Fuego, Antártida e Islas del Atlántico Sur (UNTDF), Argentina. riturraspe@untdf.edu.ar. * Autor para correspondencia

2 Instituto de Humanidades, CONICET / Universidad Nacional de Córdoba, Argentina. lucia.fank@gmail.com

3 Instituto de Ciencias Polares, Ambiente y Recursos Naturales, Universidad Nacional de Tierra del Fuego, Antártida e Islas del Atlántico Sur (UNTDF), Argentina. aurciuolo@untdf.edu.ar

4 Instituto de Ciencias Polares, Ambiente y Recursos Naturales, Universidad Nacional de Tierra del Fuego, Antártida e Islas del Atlántico Sur (UNTDF), Argentina. rlofiego@untdf.edu.ar
\end{abstract}


analysis of satellite images is used to consider three periods related to changes in national policies for industrial development. The space-temporal analysis indicates a strong link between applied policies and the dynamic of urban growth and natural land occupation. Urban expansion involved the loss of one-third of the wetland and this includes fragmented units. Urban settlements on wetlands demand large amounts of gravel and soil to raise the land level and this represents a significant environmental externality to consider. Finally, informal settlements and a lack of planning are factors than increase wetland loss.

Keywords: wetlands; urban expansion; Río Grande; Tierra del Fuego; coasts; estuaries; wet meadows.

\section{Introducción}

Las zonas costeras presentan una diversidad de humedales de especial importancia para la población y para la biodiversidad existente en estas áreas, cuyas funciones son ampliamente reconocidas. En el caso de ambientes urbanos y periurbanos, dichas funciones adquieren relevancia por los beneficios que le brindan a la población, dado que contribuyen a la salud pública e incrementan la calidad de vida de los ciudadanos (Bolund \& Hunhammar, 1999). A pesar de ello, las actividades humanas propias del crecimiento urbano provocan directa o indirectamente muchas de las tensiones que afectan a la sostenibilidad de estos ecosistemas. La urbanización ejerce una influencia significativa en la estructura y función de los humedales costeros (Lee et al., 2006) y según Rojas, Munizaga, Rojas, Martínez \& Pino (2019), es la principal causa de su pérdida en áreas metropolitanas. Los múltiples efectos combinados de la urbanización han llevado a la reducción, alteración y fragmentación de los ecosistemas (Cosentino \& Schooley, 2018; Pauchard, Aguayo, Peña \& Urrutia, 2006). Además de causar pérdida directa de hábitat, impacta en la estructura y función de los humedales costeros, a través de su efecto en el régimen hidrológico, principal conductor de la dinámica de estos espacios (Lee et al., 2006). Ehrenfeld (2000) describe los efectos de la urbanización en la hidrología y geomorfología de zonas húmedas en ciudades costeras, distinguiendo entre cambios directos e indirectos y analizando las restricciones para su restauración. El continuo crecimiento poblacional en el litoral marítimo implica que los humedales estarán allí sometidos a impactos crecientes (Callaway $\&$ Zedler, 2004), por lo cual es fundamental su estudio desde una perspectiva temporal.

El problema de la pérdida de estos ambientes por efectos de la urbanización ha sido ampliamente analizado a nivel global. Las zonas litorales están entre las regiones más urbanizadas del mundo y un $30-40 \%$ de la población mundial vive dentro de los $100 \mathrm{~km}$ de la línea de costa. Se estima que hacia 2014 Asia perdió humedales costeros a una tasa anual del 1,15\% del área total (Lin \& Yu, 2018), superando a Europa $(0.99 \%)$ y a Norte América $(0,51 \%)$. Los autores analizan la pérdida playas en ciudades chinas en 1990-2015, vinculando sus causas al gran desarrollo económico en el período. España perdió el 45\% de los servicios ecosistémicos de los humedales costeros hacia 2013 (Gardner et al., 2015). La información regional y nacional sobre pérdida de dichos ecosistemas suele diferir según las fuentes, debido a la carencia de datos precisos sobre la cobertura original y evolución. De allí la importancia de la información homogeneizada para diferentes fechas derivada del Proyecto europeo CORINE Land Cover, CLC (Büttner et al., 2004), que ha facilitado la evaluación del gran impacto de la urbanización; por ejemplo en Madrid, donde la mitad del territorio sufrió la transformación de un uso del suelo a otro en un intervalo de 24 años (Gallardo \& Vega, 2012). También en base a datos de CLC, Mirailles García et al. (2012) muestran que en las provincias de Castellón, Valencia y Alicante, la actividad inmobiliaria entre 1990 y 2006 modificó 20.892 ha de la zona costera y 24.107 ha de ambientes naturales pre-costeros, señalando que parte de los espacios alterados nunca fueron usados, debido a la crisis inmobiliaria de 2008.

Autores como Pauchard et al. (2006) observan que la urbanización tiene distintos efectos sobre los humedales costeros en países desarrollados que en aquellos en desarrollo, donde el crecimiento poblacional se sigue concentrando en los núcleos urbanos, con deficiente planificación y control de la situación. Moreno-Casasola et al. (2019) estudiaron humedales del litoral de México, resaltando que es necesario trabajar en el reconocimiento institucional de estos ecosistemas, para que su manejo sea considerado en las políticas públicas y en el sistema nacional de conservación.

Pauchard et al. (2006) analizan los efectos de la urbanización sobre la biodiversidad en Latinoamérica, en particular en el caso de Concepción, Chile donde reportan aumento de especies exóticas y reducción de nativas ante el avance de la urbanización y la actividad agrícola. También en Concepción, Smith Guerra \& Romero (2009) indican una alarmante reducción, por igual motivo, de las áreas de alta calidad ambiental del paisaje. Novoa et al. (2020) analizan dos humedales con distinto grado de urbanización en la costa pa- 
cífica de Chile, resaltando su afectación debido al crecimiento de la población y a la falta de planificación. Rojas \& Abad (2019) muestran importantes cambios en 1991-2016 en el humedal Eten, refugio de aves migratorias en Perú, por presiones de la urbanización, la agricultura y la ganadería, que alteraron la dinámica hidrológica de sus aportes.

En Bahía Blanca, Argentina, la concentración de infraestructura costera, el dragado y relleno artificial, así como la contaminación y la introducción de especies exóticas son factores principales de degradación del estuario (Speake, Carbone, \& Spetter, 2020).

El estudio de los impactos del crecimiento de ciudades latinoamericanas sobre estos ecosistemas presenta además particular interés, por las características de la expansión de las mismas, asociada a fenómenos de informalidad en el acceso al suelo, ocupando áreas naturales y rurales.

En la Provincia de Tierra del Fuego, Antártida e Islas del Atlántico Sur, Argentina (en adelante Tierra del Fuego), situada en una zona insular al sur del Estrecho de Magallanes, así como en la Patagonia continental, los principales centros urbanos se ubican en el litoral marítimo, en proximidades de cursos permanentes que aseguran la disponibilidad de agua dulce. Tal es el caso de la ciudad de Río Grande, asentada en el ambiente de estepa semiárida en los comienzos del siglo XX, en la margen norte de la boca del estuario del río homónimo, principal curso de agua de la Isla Grande de Tierra del Fuego y fuente de agua potable de la ciudad (Figura 1).

El largo tramo costero urbano comprende los estuarios de los ríos Grande y Chico y es de gran relevancia internacional como hábitat de especies de aves playeras migratorias. Esto motivó su inclusión en el área protegida provincial "Reserva Costa Atlántica" (Figura 2), declarada sitio RAMSAR desde 1995. El playero rojizo Calandris canutus rufa, migra desde el Ártico canadiense en busca de alimento en un llamativo trayecto. Entre 2000 y 2002 su población global se redujo notablemente y el número de individuos que arribaron en 2002 a Tierra del Fuego disminuyó en un 50 \% (Baker et al., 2004). La costa urbana de Río Grande sería un sitio clave de alimentación, ya que posteriormente se estabilizó allí el número de arribos, mientras que declinó en otras escalas. Ello indica la preferencia de estas aves por el sitio, ante la disponibilidad de alimento (Escudero, Navedo, Piersma, De Goeij \& Edelaar, 2012).

A diferencia de otras ciudades del litoral atlántico patagónico, el entorno riograndense presenta gran extensión de humedales continentales: vegas, lagunas y arroyos. En regiones semiáridas y áridas, donde el balance hídrico es deficitario, adquieren relevancia adicional por su contraste con el entorno en materia de reservas de agua dulce, biodiversidad, productividad, contribución a la diversificación del paisaje y generación de microclimas (Casas et al., 2003).

A partir del establecimiento por Ley No 19.640 (Información legislativa del Ministerio de Justicia, 1972) de un régimen especial fiscal y aduanero para Tierra del Fuego, Río Grande modificó su perfil productivo, históricamente anclado en la actividad ganadera e hidrocarburífera, para transformarse en la capital industrial de la región. El proceso de industrialización abarcó períodos de expansión y decaimiento, según las políticas nacionales vigentes, generando migración de trabajadores desde provincias argentinas y países limítrofes. El proceso de producción del espacio urbano, vinculado al crecimiento demográfico tras los cambios en la matriz productiva, provocó una gran expansión en un contexto de escasa planificación y situaciones de informalidad (Fank, 2019). En el año 2000 fue sancionado por Ordenanza 1.258 el primer instrumento de planificación de la ciudad, que pronto quedó desactualizado, siendo sustituido en 2011 por el Plan de Desarrollo Territorial (Ordenanza 2.863). En este contexto, en 2012 se otorgó el carácter de Reserva Natural Urbana a Punta Popper y a laguna Los Patos (Figura 2).

El reclamo de suelo urbano por parte de la población ante el municipio, llevó a la progresiva urbanización de distintos humedales. Asimismo, ante la necesidad de vivienda, proliferaron los asentamientos informales en estos espacios naturales.

Collantes, Anchorena, Stoffella, Escartín \& Rauber (2009) analizaron efectos de las actividades antrópicas sobre el estuario del río Grande y zonas aledañas entre 1970 y 2000, concluyendo que el área resultó severamente degradada, con desaparición de hábitats estratégicos y evidencias de eutrofización por descarga de residuos orgánicos. Con relación al mismo sector, Lofiego, Noir, Urciuolo \& Iturraspe (2009), reportan importante avance de la urbanización sobre vegas en 2000-2008 (375 ha) y contaminación orgánica en el estuario por vertidos cloacales en base a muestreos y análisis de laboratorio. Sobre la extracción de áridos que afecta la costa urbana, Fink \& Giomi (2019) sostienen que se trata de un conflicto urbano-ambiental donde se disputan apropiaciones y dominaciones territoriales. No obstante estos estudios, aún no se cuenta 
con un análisis integral de los humedales urbanos y periurbanos de Río Grande. Si bien la informalidad asociada a las migraciones generadas por políticas de promoción se ha estudiado como fenómeno urbano (Fank, 2019), su vínculo con los ambientes naturales constituye un aspecto central, del cual aún se desconocen sus verdaderos alcances. Para su evaluación, es necesario cuantificar la extensión espacial de la pérdida de humedales en base a períodos de análisis (Mao et al., 2018) relacionados con la expansión urbana y con fluctuaciones de las políticas de promoción industrial.

El presente trabajo, tiene como objetivo evaluar los cambios físicos que los humedales de la ciudad de Río Grande y su entorno experimentaron en diferentes períodos por el proceso de crecimiento urbano, considerando factores agravantes de sus pérdidas y con un enfoque comparativo con problemas similares reportados en otros lugares del mundo.

\section{Metodología}

\subsection{El área de estudio}

Comprende el actual desarrollo de la mancha urbana de la ciudad de Río Grande (Tierra del Fuego, Argentina) y su periferia, para lo cual se ha definido un sector de 31.558 ha (Figura 1) que involucra la zona costera y el área terrestre occidental adyacente a la ciudad, rica en humedales, entre los que prevalecen vegas, lagunas, cursos de agua, estuarios, playa y plataforma de abrasión, ambientes que se describen en el ítem 3.1. La zona de estudio comprende el espacio que a mediano y largo plazo presenta potencialidad de ser urbanizado. Incluye el área terrestre adyacente a la costa en un ancho de 6 a $7 \mathrm{~km}$, que se amplía en la zona del estuario, ya que es previsible la expansión hacia el oeste en este sector, por donde ingresa la ruta $\mathrm{n}^{\circ} 3$ desde Ushuaia. Por otra parte, se ha incluido el área marítima necesaria para la delimitación de la plataforma de abrasión.

Figura 1. Ubicación del área de estudio

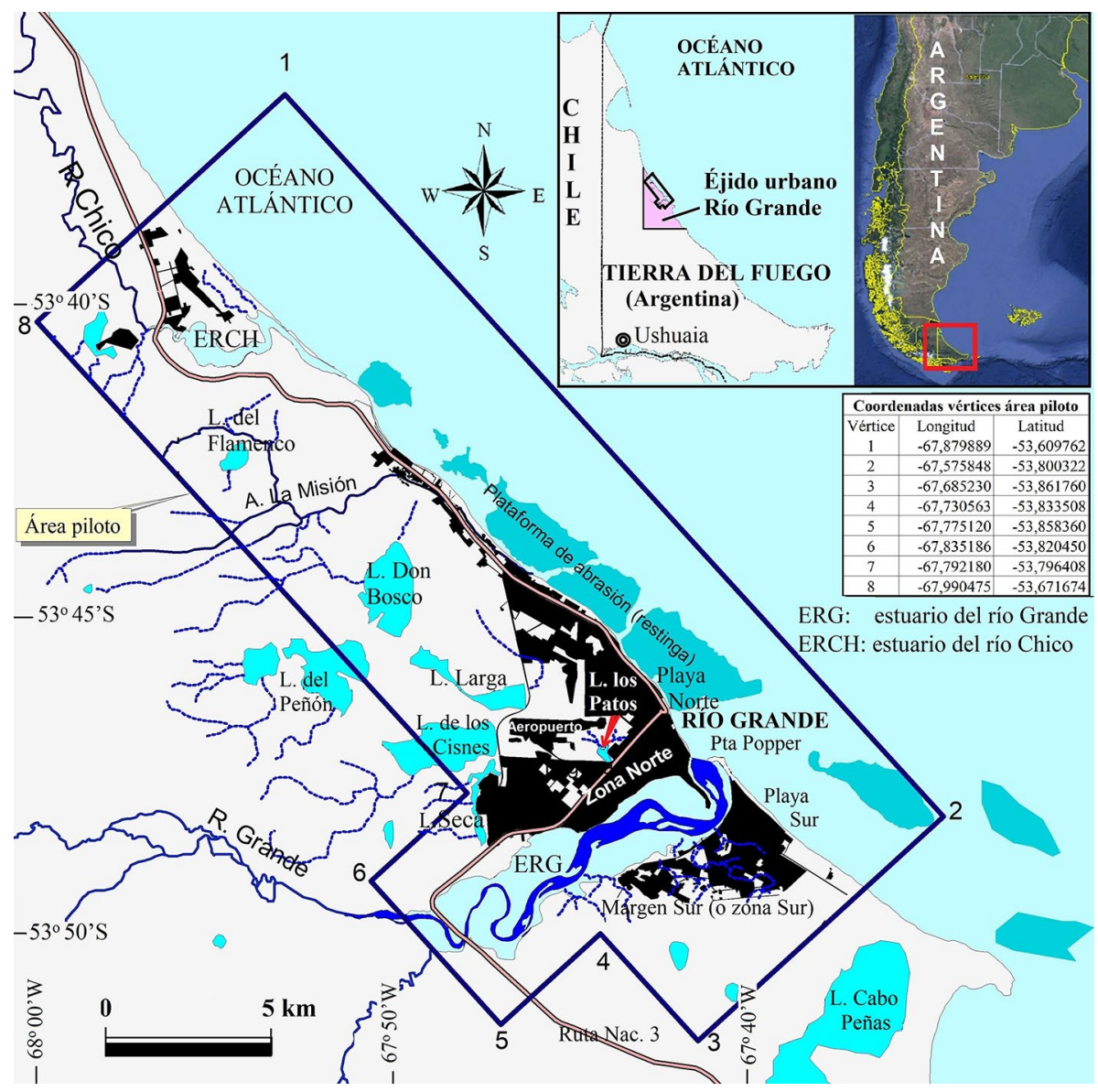

Fuente: Google Earth. Elaboración propia 
Se espera que la cartografía de humedales resultante del presente estudio sea de utilidad para la toma de decisiones relativas a la zonificación y distribución de la infraestructura urbana en el futuro, incorporando la perspectiva ecosistémica y su conservación.

La ley provincial № 32 (Gobierno de Tierra del Fuego, Antártida e Islas del Atlántico Sur-Poder judicial, 1992) define una extensa área de jurisdicción municipal, limitada por el océano Atlántico, el meridiano $67^{\circ} \mathrm{W}$ y el paralelo $54^{\circ} \mathrm{S}$. Comprende 94.000 ha de superficie y $70 \mathrm{~km}$ de costa. Aunque la mancha urbana abarca menos del $4 \%$ de dicha área, se extiende a lo largo de un litoral de $27 \mathrm{~km}$, lo cual es evidencia de su fuerte condición marítima. Con valores anuales de $5,5^{\circ} \mathrm{C}$ de temperatura, $330 \mathrm{~mm}$ de precipitación y viento sostenido del oeste, resulta un clima semiárido frío, con fuerte déficit hídrico en verano. El ámbito rural colindante corresponde a extensos predios privados dedicados a la ganadería extensiva ovina y bovina.

La extracción de oro, la actividad de la Misión Salesiana y la ganadería, dieron origen al asentamiento de la ciudad, que creció notablemente a partir de 1972 debido al proceso de industrialización de Tierra del Fuego iniciado ese mismo año, cuando contaba con 7.754 habitantes (Instituto Nacional de Estadística y Censos, INDEC, 1974). El último Censo (INDEC, 2010) registró una población de 66.475 habitantes en 2010 y según proyecciones oficiales, ascendería a 90.000 en 2020.

Figura 2. Localización de las áreas protegidas. Reserva Costa Atlántica y Reservas Naturales Urbanas (RNU) Punta Popper (A) y laguna los Patos (B)

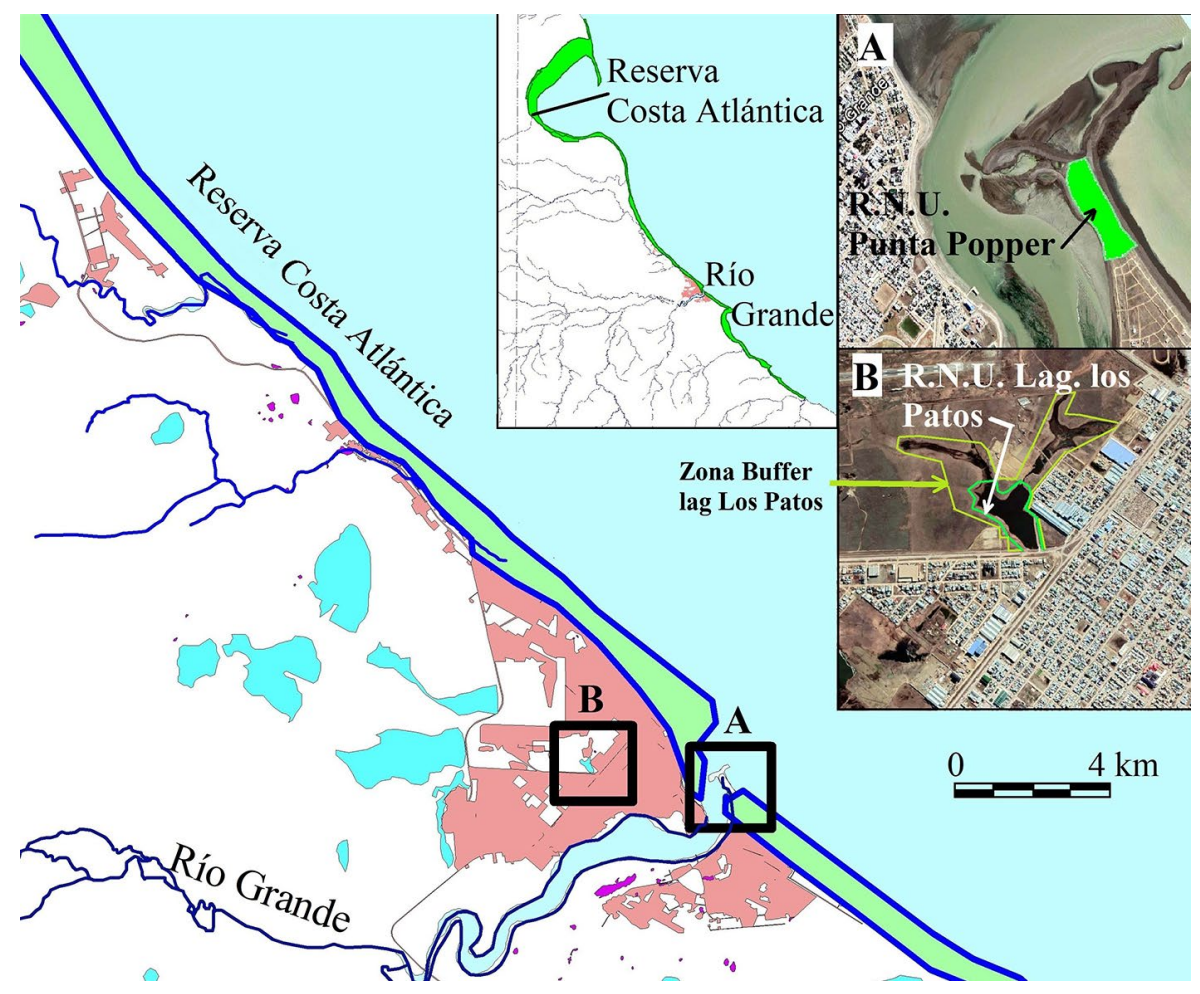

Fuente: Secretaría de Ambiente de Tierra del Fuego y Municipalidad de Río Grande; Google Earth. Elaboración propia

\subsection{Desarrollo metodológico}

Fue necesario realizar un diseño metodológico que cubra necesidades de información, ante la falta de un inventario de humedales y de una plataforma como la del proyecto europeo CORINE Land Cover, que en el ámbito europeo desde el año 1990 suministra información comparable sobre ocupación del suelo entre distintos períodos de tiempo y permite su utilización a distintas escalas para el análisis de cambios en los ecosistemas (Guaita, López \& Prieto, 2008).

Dicho diseño aborda luego, el análisis integral del estado de humedales afectados por un crecimiento urbano de singular intensidad, sujeto a políticas oscilantes de promoción industrial, con rasgos particulares, como la informalidad y el déficit de planificación. Se entiende que la estrategia diseñada podría ser 
replicable al tratamiento de similares problemas en el ámbito de Latinoamérica y de otras regiones donde se presenten similares condicionantes.

La investigación se desarrolló en base a tres ejes principales: 1) identificación, clasificación y delimitación de los humedales urbanos y periurbanos de la ciudad de Río Grande; 2) análisis del crecimiento urbano y de las áreas alteradas, a partir de 1972, con la vigencia de la ley de promoción industrial; 3) análisis de la afectación de humedales por el crecimiento urbano. El análisis espacial relativo a estos ejes se basó en el material detallado en la Tabla 1.

Tabla 1. Material de teledetección utilizado

\begin{tabular}{|l|l|l|l|}
\hline \multicolumn{1}{|c|}{ Material } & \multicolumn{1}{|c|}{ Fecha } & Escala/Resolución & \multicolumn{1}{c|}{ Uso } \\
\hline $\begin{array}{l}\text { Fotografías aéreas del Servicio } \\
\text { de Hidrografía Naval (SHN) }\end{array}$ & 12 feb1970 & $1: 20.000$ & $\begin{array}{l}\text { Delimitación de humedales en zonas urbanizadas antes } \\
\text { de 1985 y del área urbana hacia 1970 }\end{array}$ \\
\hline Fotografías aéreas SHN & $16 \mathrm{sep} 1991$ & $1: 20.000$ & Delimitación de expansión urbana en 1991 \\
\hline Landsat 5 TM & $05 \mathrm{abr1985}$ & $30 \mathrm{~m}$ & $\begin{array}{l}\text { Análisis no supervisado para delimitación de humedales } \\
\text { (imagen TM más antigua disponible) }\end{array}$ \\
\hline SPOT 3 HRV multiespectral & $18 / 1 / 1995$ & $\begin{array}{l}10 \mathrm{~m} \text { (remuestreo del } \\
\text { original de 20m) }\end{array}$ & $\begin{array}{l}\text { Análisis no supervisado para delimitación de humedales } \\
\text { (complemento) }\end{array}$ \\
\hline Landsat 5 TM & $14 / 12 / 2001$ & $30 \mathrm{~m}$ & Delimitación de expansión urbana 2001 \\
\hline SRTM & 2000 & $90 \mathrm{~m}$ & Cartografía de humedales (depuración) \\
\hline $\begin{array}{l}\text { Imágenes HR varias disponi- } \\
\text { bles en Google Earth }\end{array}$ & $2006-2020$ & $\sim 1 \mathrm{~m}$ & $\begin{array}{l}\text { Delimitación de expansión urbana 2020 y apoyo general } \\
\text { a delimitación de humedales y expansión urbana. }\end{array}$ \\
\hline
\end{tabular}

Elaboración propia

\subsubsection{Identificación, delimitación y clasificación de humedales}

Para la clasificación de humedales se utilizó el sistema definido por Ramsar (Scott \& Jones, 1995; Secretaría de la convención Ramsar, RAMSAR, 2013), dado que proporciona un marco amplio para identificar con rapidez los principales tipos de humedales representados en cada sitio y facilita señalar el "tipo de humedal dominante". Se trabajó a nivel de macro y mesoescala. A nivel macro se utilizó además la clasificación hidrogeomórfica HGM (Brinson, 1993) para agrupar unidades identificadas en clases funcionales de mayor nivel jerárquico. Para el caso de humedales costeros, se complementó con la clasificación basada en geomorfología (CBG) propuesta por Semeniuk \& Semeniuk (2016) ya que HGM no cuenta con clase marina.

Se estableció una línea de base del estado de zonas húmedas en 1972, a partir del análisis espacial del sector de 31.558 ha definido a tales fines (Figura 1) que incluye zonas con potencialidad de ser afectadas por la expansión futura.

El sistema de información geográfica fue trabajado en base al software QGIS V3.12.

La delimitación y cartografía de humedales se realizó a partir del uso de técnicas combinadas:

- Análisis espectral a través del análisis no supervisado de imágenes Landsat 5 TM. Se usó el Plugin de Clasificación Semiautomática V. 7.0.15 para QGIS, con el método de clasificación Isodata.

- Depuración de datos a partir del Modelo Digital del Terreno (SRTM 2000 v4.1)

- Análisis visual de Imágenes alta resolución.

- Validación en terreno.

La imagen Landsat TM más antigua es de 1985, o sea posterior al inicio de la expansión urbana. Por ello, la delimitación de humedales urbanizados antes de 1985 se realizó en base al análisis visual de fotografías aéreas. Se escogió la técnica de análisis no supervisado, dado el marcado contraste entre la respuesta espectral de las unidades a identificar, como vegas, coironales semiáridos, urbanización, etc. No obstante, el modelo digital del terreno se usó para depurar la clasificación obtenida de vegas, ya que la distribución de éstas correlaciona muy bien con la topografía. Se complementó esta información con datos de trabajos preexistentes (Anchorena et al., 2009; Lofiego et al., 2009) y entrevistas a actores gubernamentales y pobladores locales sobre zonas tempranamente urbanizadas. Controles de campo permitieron ajustar resultados. 
A los efectos de la determinación de la tasa anual de pérdida de superficie de humedales en 1972-1991, se estimó la ya afectada en 1972. La situación del viejo casco urbano, en terrenos elevados respecto del entorno, era poco favorable a la presencia de vegas, por lo tanto los efectos negativos sobre estos ecosistemas correspondieron a tramos de infraestructura vial y aeroportuaria. Los espacios naturales remanentes permitieron identificar áreas en donde existían zonas húmedas. Las ocupaciones de espacios de playa se evidenciaron por la alteración de la continuidad del bien definido límite playa-estepa, y en relación al estuario, mediante la identificación de una primera línea de avance sobre el mismo, materializada por viviendas informales sobre rellenos artificiales no autorizados. Fue éste el comienzo de un proceso continuo y progresivo de ocupación informal del humedal.

\subsubsection{Análisis de la expansión urbana y del cambio de cobertura de suelo.}

A través del análisis de fotografías aéreas e imágenes de satélite consignadas en la Tabla 1 se determinó la expansión urbana en los distintos períodos del proceso de industrialización de Tierra del Fuego. Los cortes temporales se definieron en función de los distintos períodos de dicho proceso, según políticas nacionales que generaron impulso o desaliento de la actividad:

- 1972-1991: Etapa de industrialización

- 1991-2001: Etapa de recesión de la actividad industrial

- 2001-2020: Etapa de re-industrialización (nuevas tendencias recesivas desde 2016)

El área considerada como expansión para distintos períodos de tiempo es la cantidad de suelo que se ha transformado en área urbana (Lanfranchi et al., 2018). Abarca tanto tejidos residenciales (incluye subdivisiones formales, grandes parcelas residenciales, viviendas sociales, villas y asentamientos reconocidos en el ATLAS ID de Argentina) como áreas comerciales, superficies cubiertas por calles y avenidas, espacios y equipamientos públicos, así como ciertas áreas que si bien no están urbanizadas, se encuentran en la zona de influencia y se ven directamente afectadas por la expansión, tales como: vacíos urbanos de superficie menor a 1 ha, canteras urbanas, plantas de residuos sólidos y el área del autódromo municipal.

Los datos obtenidos mediante diferentes estrategias fueron cotejados con otras fuentes de información primaria y secundaria. Las primeras corresponden a entrevistas con informantes claves de la Municipalidad de Río Grande y otros referentes locales. Las fuentes secundarias incluyen informes y mapas antiguos obtenidos en dependencias de la Dirección General de Recursos Hídricos de Tierra del Fuego (DGRH) y del Municipio de Río Grande.

El crecimiento medio anual $C$ [ha/año] para cada período se calculó mediante la expresión:

$$
C=\frac{(A 2-A 1) \cdot 100}{n}
$$

La tasa de crecimiento anual $T[\%]$ es: $T=\left(\sqrt[n]{\frac{A 2}{A 1}}-1\right) \cdot 100$

A1 y A2: superficie [ha] al inicio y fin del período de análisis y $n$ : número de años.

Se ha determinado también la evolución del cambio de cobertura del suelo (CCS). Esto incluye el área de expansión urbana propiamente dicha y por otra parte, toda superficie no considerada como propia de la expansión (áreas rurales periféricas o vacíos urbanos), cuya cobertura original haya experimentado alteraciones significativas. Involucra por ejemplo, áreas en preparación para la posterior urbanización, no computadas como parte de la expansión, así como aquellas que, sin ser canteras, hayan sido objeto de extracción o remoción de suelo.

Asimismo, se identificaron y delimitaron los vacíos urbanos sin intervenciones directas que produjeran CCS, pero aislados total o parcialmente por estructuras urbanas, implicando fragmentación o aislamiento del remanente de humedal que pudieran incluir.

\subsubsection{Análisis de la afectación de humedales por el crecimiento urbano}

Si bien se reconocen cambios de distinto tipo debidos a la urbanización en estos ecosistemas, como aquellos relativos a la pérdida de calidad ambiental, el presente trabajo se focaliza en la determinación, en 
cada uno de los períodos, de las modificaciones físicas que provocaron pérdida de superficie o alteraciones en la geomorfología y en la hidrología (Ehrenfeld, 2000).

En el análisis se distinguieron dos niveles de afectación: a) cambios directos: pérdida de superficie de humedales en cada período debido a CCS por urbanización, movimiento de suelos preparatorio para nuevas urbanizaciones o infraestructuras, extracción de suelo, etc.; b) cambios indirectos: el aislamiento o fragmentación en vacíos urbanos o periurbanos que no afectan la cobertura del suelo. Según Bernal Jaramillo (2006) "es muy probable que en los fragmentos resultantes no se den los procesos que le otorgan integridad ecológica al humedal, y que éstos carezcan de la viabilidad para cumplir las funciones propias de estos ecosistemas" (p. 49), lo que implica degradación de los mismos, particularmente en vegas y playas. Se asignaron categorías de fragmentación alta y moderada: alta para fragmentos en vacíos urbanos $<20$ ha; en tanto que en vacíos $\geq 20$ ha la categoría se analizó en cada caso en base a la extensión del fragmento, su geometría y emplazamiento respecto a la dirección del flujo que lo alimenta.

Cartografiadas las áreas urbanas con CCS, se intersectó esta capa con la de humedales existentes en 1972 para obtener la cronología de las pérdidas. Las áreas fragmentadas se vincularon a las últimas dos décadas exclusivamente, ya que los límites que definen la condición actual de cada fragmento responden a distinta temporalidad y en casi todos los casos el proceso se completó en este último período.

Paralelamente, se realizaron entrevistas a actores identificados como relevantes: especialistas de la Municipalidad de Río Grande y de la Universidad Nacional de Tierra del Fuego, que aportaron información sobre la evolución de la alteración física de humedales y otros impactos en los mismos derivados de la dinámica urbana.

\section{Resultados}

\subsection{Identificación y clasificación de humedales}

Los humedales identificados fueron inicialmente agrupados de acuerdo al sistema Ramsar (RAMSAR, 2013) en sus tipos principales a macro escala: Marino-costeros (Tabla 2) y continentales (Tabla 3). A los fines de su caracterización y comprensión funcional, se definieron para cada tipo clases de acuerdo a criterios hidro-geomorfológicos y geomorfológicos para el caso de los marino-costeros (clasificaciones HGM y CBG).

Tabla 2. Clasificación de humedales marino/costeros de Río Grande

\begin{tabular}{|l|l|l|}
\hline \multicolumn{1}{|c|}{ Clase CBG } & \multicolumn{1}{|c|}{ Humedal identificado } & \multicolumn{1}{c|}{ Tipo humedal según Clasificación Ramsar } \\
\hline \multirow{4}{*}{ Estuario } & & $\begin{array}{l}\text { F- Estuarios } \\
\text { G- Bajos intermareales de lodo, arena o con suelos salinos }\end{array}$ \\
& $\begin{array}{l}\text { Estuario Río Grande (ERG) } \\
\text { H- Pantanos y esteros intermareales } \\
\text { Estuario Río Chico (ERC) }\end{array}$ & $\begin{array}{l}\text { M- Ríos-arroyos permanentes } \\
\text { J- Lagunas costeras salobres/saladas }\end{array}$ \\
\hline \multirow{4}{*}{ Costa abierta } & Plataforma de abrasión N y S (PAN y PAS) & D- Costas marinas rocosas \\
\cline { 2 - 3 } & Playa de arena y grava N y S (PLN y PLS) & E- Playas de arena o guijarros \\
\cline { 2 - 4 } & Playas bajo aguas someras (AS) & A- Aguas marinas someras permanentes \\
\hline
\end{tabular}

Elaboración propia

Tabla 3. Humedales continentales adyacentes a la zona costera

\begin{tabular}{|l|l|l|}
\hline \multicolumn{1}{|c|}{ Clase HGB } & \multicolumn{1}{|c|}{ Humedal identificado } & \multicolumn{1}{c|}{ Tipo humedal según Clasificación Ramsar } \\
\hline $\begin{array}{l}\text { Humedales de } \\
\text { depresiones }\end{array}$ & $\begin{array}{l}\text { Vegas húmedas y subhúmedas Sector Margen } \\
\text { N y S }\end{array}$ & $\begin{array}{l}\text { Ts- Pantanos/esteros/charcas estacionales/ intermitentes de } \\
\text { agua dulce sobre suelos }\end{array}$ \\
\hline \multirow{2}{*}{$\begin{array}{l}\text { Humedales } \\
\text { lacustres }\end{array}$} & Lagunas urbanas & O- Lagos permanentes de agua dulce \\
\cline { 2 - 3 } & Lagunas periurbanas & P- Lagos estacionales /intermitentes de agua dulce \\
\hline $\begin{array}{l}\text { Humedales } \\
\text { fluviales }\end{array}$ & Arroyos urbanos y periurbanos & P- Lagos estacionales /intermitentes. de agua dulce \\
\cline { 3 - 3 } & & M- Ríos/arroyos intermitentes \\
\hline
\end{tabular}

Elaboración propia

Se describen a continuación las características de cada tipo de humedal identificado. 


\subsubsection{Estuarios. Ríos Grande y Chico (ERG y ERCH)}

Los estuarios son zonas de transición entre el ámbito fluvial y marítimo, donde la descarga fluvial asegura un aporte continuo de sedimentos, materia orgánica y nutrientes, que favorece el desarrollo de comunidades de valor ecológico, especializadas y adaptadas a las variaciones de salinidad (Perillo \& Piccolo, 2013). En los estuarios del caso de estudio se aprecian humedales de franjas (Pratolongo et al., 2013), sometidos a flujos bidireccionales resultantes de la acción de mareas de $6 \mathrm{~m}$ de amplitud media y 9,40 m de máxima, con influencia hasta 10 kilómetros hacia el interior. La primera franja, que incluye el lecho fluvial y adyacencias es la de bajos intermareales de lodo; la intermedia, consiste en marismas pobladas de Sarcocornia spp.) y finalmente, la marisma alta, cubierta por "Pastizales Salinos" de Puccinellia spp y Sarcocornia spp., con coberturas cercanas al 90 \% (Collantes et al., 2009). Las dos últimas fajas mencionadas adquieren mayor definición y expansión hacia los sectores mediales del estuario. El ERG se destaca por su gran extensión (1.910 ha) y amplia zona intermareal, de hasta $3 \mathrm{~km}$ de ancho. Descarga en él el río más importante de Tierra del Fuego, con caudal medio de $45 \mathrm{~m}^{3} / \mathrm{s}$ y cuenca de aporte de $8.700 \mathrm{~km}^{2}$. El volumen de intercambio en el estuario entre mareas ordinarias, de 80 millones de $\mathrm{m}^{3}$, genera un flujo bidireccional 70 veces mayor al del caudal fluvial. El ERCH, cuyo sistema fluvial es más reducido, tiene 252 ha. Presenta una barra costera de $150 \mathrm{~m}$ de ancho y 2,5 km de longitud que desvía el cauce principal hasta la desembocadura.

\subsubsection{Costa abierta: plataforma de abrasión, playa de arena y grava, aguas someras}

Bujalesky (2007) describe la geomorfología costera local como un complejo de aguas poco profundas y tierra emergida, compuesto por la plataforma de abrasión, la playa y las dunas y planicies de la paleoplaya. Estos componentes se corresponden con humedales marino-costeros.

La plataforma de abrasión se conforma por rocas sedimentarias de superficie irregular, que en bajamar dan lugar a planicies encharcadas, pozas, grietas y canales que retienen agua y fauna bentónica de pequeño tamaño, que junto con moluscos adheridos a las rocas constituyen alimento de las aves playeras de la reserva.

Las playas intermareales de grava y arena gruesa están afectadas por procesos de erosión y deposición de sedimentos. La fuente de este material procede de formaciones del litoral norte de Tierra del Fuego y en menor medida de aportes locales (Bujalesky, 1997). Como consecuencia de la intensidad de mareas, Isla y Bujalesky (2005) reportan un comportamiento "estuarial" del flujo subterráneo en estas playas debido al flujo bidireccional y a la variación de la concentración de sales. En discontinuidades de la plataforma de abrasión se observan playas de grava y arena cubiertas por aguas someras, que alcanzan mayor desarrollo junto a la boca del ERG, probablemente por la carga de sedimento que aporta el río.

La playa y la restinga, de débil pendiente, forman un extenso ecosistema intermareal de más de $1.600 \mathrm{~m}$ de ancho desde la línea de costa. Fuera del alcance de las mareas se extiende la paleoplaya holocénica, con sucesión de dunas y planicies en suave inclinación y con presencia de agua dulce, de origen subterráneo o superficial, siendo destacable el tramo final del arroyo La Misión. La disponibilidad de agua y alimento da lugar a la abundancia y diversidad de aves. Aunque la paleoplaya alcanza un mayor desarrollo al norte del río Chico, sólo se ha identificado allí como humedal la faja de $700 \mathrm{~m}$ de ancho desde la línea de costa que incluye dos canales de desborde de mareas con descarga al ERCH.

En la boca del ERG se desarrolla la Punta Popper, con características diferenciadas por los aportes de agua dulce, nutrientes y sedimentos del río Grande, cuya dinámica se combina con la energía del oleaje, las mareas y las corrientes litorales, motivando paisajes de particular morfología con abundancia de aves. La erosión y deposición del material granular movilizado por las fuerzas mencionadas motivan el cambio continuo de la morfología de la espiga terminal intermareal, con una dinámica que modifica el ancho de la boca del estuario.

\subsubsection{Humedales de depresiones: vegas sector $N$ y $S$}

Las vegas, también denominadas mallines en territorios patagónicos con influencia de la cultura mapuche, son humedales dependientes del aporte de aguas subterráneas, debido al carácter deficitario del balance hídrico. Se presentan por lo tanto en zonas bajas del terreno, donde el nivel freático aflora o está próximo a la superficie; frecuentemente adyacentes a sistemas de drenaje (Iturraspe, 2016), son comunidades edáficas cuyo terreno está temporal o permanentemente inundado o anegado (Collantes, et 
al., 2009) y se diferencian netamente de las áreas circundantes por su tipo de suelo altamente orgánico, con alto contenido de humedad y flora característica. Son el tipo de humedal dominante en la estepa fueguina. Collantes, Braun, Escartín, Cingolani \& Anchorena (2005) distinguen vegas húmedas y subhúmedas, según la permanencia del estado de saturación, dependiente de la situación topográfica. Un mismo humedal suele incluir una zona de vega húmeda y otra de vega sub-húmeda. El relieve ondulado favorece su desarrollo en las zonas bajas, donde aflora la capa freática. Su morfología es longitudinal, en coincidencia con redes de drenaje y áreas deprimidas mal drenadas. Corresponden al tipo hidrogeomórfico de depresión, pero pueden ser también de pendiente.

Ocasionalmente, cuando persiste el nivel de saturación cerca de la superficie, se pueden dar las condiciones anóxicas necesarias para la acumulación de turba y el desarrollo de turberas graminosas geogénicas (fens). En este estudio no se han distinguido las turberas de las vegas húmedas, dada la similitud en las comunidades vegetales y contenido de humedad, que hace necesario tareas de campo específicas para su identificación.

\subsubsection{Humedales lacustres: lagunas urbanas y periurbanas}

Las lagunas, muy someras, difieren entre sí en su génesis.

Las lagunas de deflación, las de mayor tamaño, situadas al oeste de la ciudad, son resultado del efecto de la intensidad y persistencia del viento. Sus cuencas son reducidas y los sistemas fluviales aportantes tienen régimen estacional. Son éstas las lagunas Don Bosco, Del Peñón, Redonda, Larga, Los Cisnes y Seca (nombradas de $\mathrm{N}$ a S). Conforman un sistema endorreico con una superficie lagunar de 2.500 ha en aguas altas, que constituye el $28 \%$ de la cuenca total (8.800 ha). Son muy sensibles a la evaporación y su balance hídrico anual es deficitario (Iturraspe \& Urciuolo, 2002). Si bien son externas a la mancha urbana, provocan inconvenientes ambientales cuando se desecan totalmente y sus lechos de sedimento fino quedan expuestos a la acción del viento, el que transporta nubes de polvo sobre la ciudad.

Las lagunas del ambiente de vegas son cuerpos pequeños, menores de 10 ha, cuyo origen está vinculado al proceso de desarrollo de la vega. El aporte de aguas subterráneas, común en este ambiente, da lugar a niveles relativamente estables a lo largo del año. Finalmente, cabe mencionar las lagunas con influencia antrópica. Las principales son la del Arroyo La Misión, que incrementó su tamaño progresivamente por la extracción de áridos en sus márgenes, y la laguna de los Patos, consecuencia de una obra vial que elevó el nivel de drenaje. Se aprecia en aerofotografías de 1970 que su sitio estaba ocupado por una gran vega con lagunas.

\subsubsection{Humedales fluviales: arroyos urbanos y periurbanos}

Además de los ríos Grande y Chico, los pequeños arroyos revisten importancia ambiental; muchos son intermitentes debido a la reducida extensión de sus cuencas y al alto déficit hídrico estival. Se congelan en invierno y en época de deshielo evacúan los excedentes hídricos. Tras esta etapa, el régimen fluvial depende de aportes de la capa freática y lluvias eventuales. Los arroyos permanentes son el de La Misión y el emisario de laguna de los Patos.

El arroyo La Misión nace al SW del área urbana. Su cuenca tiene una superficie de $65 \mathrm{~km}^{2}$ y su longitud es de $19 \mathrm{~km}$. Se estima el caudal medio en $0,20 \mathrm{~m}^{3} / \mathrm{s}$, que se usa en parte para riego de parcelas agrícolas. Su tramo final, de casi $4 \mathrm{~km}$ transcurre por el ambiente de paleoplaya en dirección paralela a la costa. Sin salida directa al mar, el arroyo descarga por percolación, a través de la barra de grava. En este tramo, muy perturbado por la actividad de las canteras, sus aguas han sido usadas para lavado de áridos.

El arroyo de la laguna de los Patos es un curso urbano permanente. Su cuenca, comprendida totalmente en el área urbana, abarca unos $6 \mathrm{~km}^{2}$.

\subsection{Delimitación y cartografía de humedales}

La cartografía elaborada sobre los humedales existentes en 1972 constituye una línea de base representativa de su extensión y distribución en un área con una riqueza en la materia, inusual en zonas semiáridas.

La delimitación de vegas se ajustó contrastando resultados del análisis espectral con el modelo digital del terreno (MDT) y el chequeo en campo de resultados. Se ha estimado el error en la identificación de vegas en $\pm 4 \%$, y en $\pm 10 \%$ en la distinción entre vegas húmedas y subhúmedas. En el caso de lagunas, sólo se contabilizaron las áreas incluidas en la zona de análisis definida (Figura 1); cada espejo de agua varía 
con el estado de almacenamiento, por lo cual se consideró una condición media para su delimitación. Los límites de estuarios han sido determinados en base al MDT según el nivel de las mareas máximas anuales, y a partir de evidencias geomorfológicas y ecológicas constatadas en terreno.

En las tablas 4 y 5 se indican las superficies de los distintos tipos de humedales marino-costeros y continentales respectivamente, determinadas en el área piloto. Han sido discriminadas por zonas Norte y Sur, según su situación respecto del ERG. Las superficies de unidades marino-costeras y continentales son equiparables (Figura 3-A) y se aprecia similitud de magnitudes entre los subtipos marino-costeros (Figura 3-B). El ámbito terrestre analizado totaliza 15.934 ha, excluyendo estuarios y playa, por contabilizarse éstos como marino-costeros. La máxima cobertura corresponde a vegas y entre ellas, a las sub-húmedas (Figura 3-C).

Tabla 4. Extensión de humedales marino costeros en el área piloto en 1972

\begin{tabular}{|l|r|r|r|}
\hline \multirow{2}{*}{ Humedales marino-costeros } & \multicolumn{3}{c|}{ Superficie [ha] } \\
\cline { 2 - 4 } & Zona Norte & Zona Sur & \multicolumn{1}{c|}{ Total } \\
\hline Estuario RG & & & 1.910 \\
\hline Estuario RCH & & & 252 \\
\hline Plataforma de abrasión N y S & 1.610 & 354 & 1.964 \\
\hline Playa N & 976 & 348 & 1.324 \\
\hline Playa S & 413 & 108 & 521 \\
\hline Total humedales Marino-costeros & & & 5.970 \\
\hline
\end{tabular}

Elaboración propia

Tabla 5. Extensión de humedales continentales en 1972 y su relación respecto del área terrestre total

\begin{tabular}{|l|r|r|r|r|r|r|}
\hline \multirow{2}{*}{\multicolumn{1}{c|}{ Humedales continentales }} & \multicolumn{3}{|c|}{ Superficie [ha] } & \multicolumn{3}{c|}{ Superficie [\%] } \\
\cline { 2 - 8 } & Zona Norte & Zona Sur & \multicolumn{1}{c|}{ Total } & Zona Norte & \multicolumn{1}{c|}{ Zona Sur } & \multicolumn{1}{c|}{ Total } \\
\hline Vegas sub-húmedas & 1.846 & 750 & 2.596 & 14,9 & 21,0 & 16,3 \\
\hline Vegas húmedas & 1.262 & 494 & 1756 & 10,2 & 13,9 & 11,0 \\
\hline Lagunas & 941 & 53 & 993 & 7,6 & 1,5 & 6,2 \\
\hline Total humedales continentales & 4.049 & 1297 & 5.345 & 32,7 & 36,4 & 33,5 \\
\hline Áreas sin humedales & 8.323 & 2.265 & 10.588 & 67,3 & 63,6 & 66,5 \\
\hline Total área terrestre analizada & $\mathbf{1 2 . 3 7 2}$ & 3.562 & $\mathbf{1 5 . 9 3 4}$ & $\mathbf{1 0 0 , 0}$ & $\mathbf{1 0 0 , 0}$ & $\mathbf{1 0 0 , 0}$ \\
\hline
\end{tabular}

Figura 3. Cobertura de humedales hacia 1972 (Río Grande y entorno)
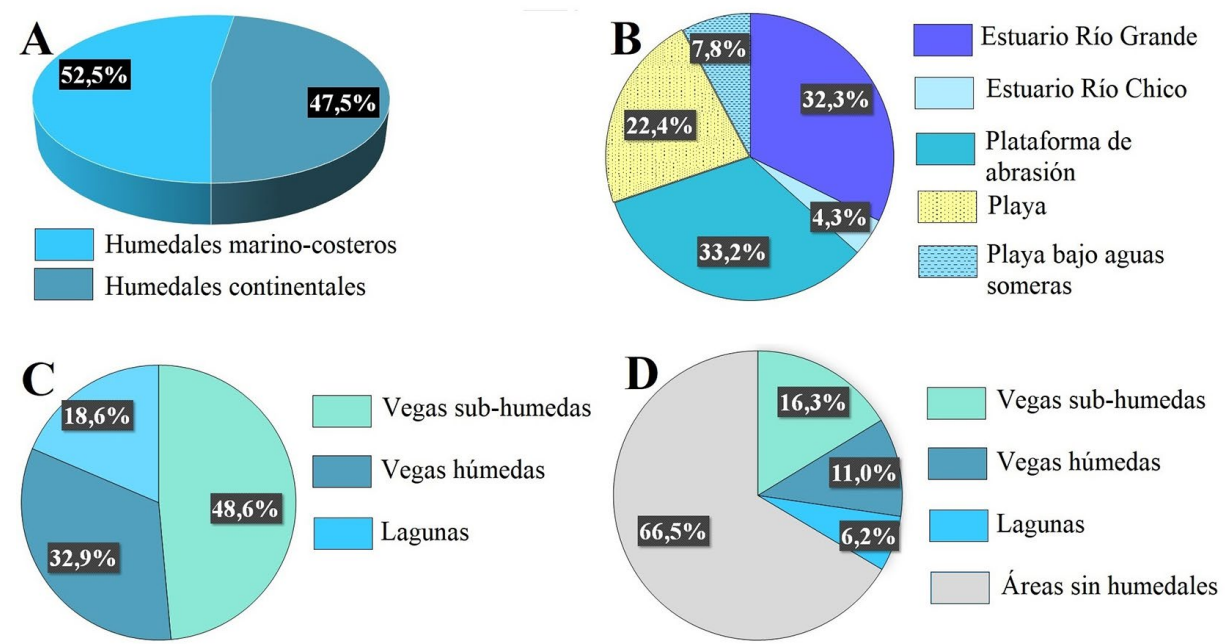

A: relación de áreas de humedales marino-costeros y continentales; B: componentes marino-costeros; C: componentes continentales; D: cobertura de zonas húmedas continentales en relación al área terrestre total. 
Comparadas ambas zonas, es mayor el área lagunar en la norte, pero es compensada por mayor manifestación de vegas en la sur. Esto es debido a las lomadas situadas entre la ciudad y laguna Cabo Peñas, que sin sobrepasar 70 m s.n.m aportan flujo superficial y subterráneo. Las vegas cubren el $25 \%$ en la zona norte y el $35 \%$ en el sector sur y en conjunto, los tipos continentales abarcan el 36,4 \% y el $32,7 \%$ del área terrestre en las zonas norte y sur respectivamente. Las áreas sin humedales corresponden a comunidades de estepa: coironal de Festuca gracillima y matorral de Chilliotrichum diffusum, suelos sin vegetación, y construcciones, con una cobertura en conjunto del 66,5 \% (Figura 3-D).

\subsection{Análisis de la expansión urbana de la ciudad de Río Grande y del cambio de cobertura de suelo relacionado.}

Con el océano Atlántico como barrera natural, los terrenos del Aeropuerto y la Armada Argentina eran en 1972 el límite norte de la expansión urbana, así como hacia el sur y hacia el oeste lo eran las tierras privadas de uso rural. Más al norte se situaba, desde principios del siglo pasado, la Misión Salesiana. Al sur del río Grande, sólo había un frigorífico que procesaba la producción ganadera. El área urbana alcanzaba entonces a 470 ha.

La instalación de industrias y la inmigración, consecuentes del régimen especial aduanero y fiscal para Tierra del Fuego establecido en 1972 produjeron la gran transformación de un pequeño asentamiento urbano en la mayor ciudad fueguina, cuya actual extensión de 2.901 ha, aumentó 517 \% respecto de 1972, a un promedio de 50,6 ha/año, y tasa del 3,86 \% anual.

Río Grande fue la principal receptora de industrias y de nueva población, con ventajas comparativas en su localización, más próxima al territorio continental, y en su topografía, por permitir un mejor aprovechamiento del espacio que la del ambiente cordillerano de Ushuaia.

\subsubsection{Evolución de la expansión urbana}

La Figura 4 y la Tabla 6 describen la secuencia temporal de la expansión urbana en 1972-2020.

La fase de industrialización (1972-1991) produjo el desarrollo inmediato del casco urbano hacia el oeste, entre la ruta $\mathrm{n}^{\circ} 3$ al norte y el ERG al sur, en donde se asentó el parque industrial. Entre éste y el casco histórico, la ciudad creció con uso residencial. Hacia el norte por acción estatal con vivienda colectiva y hacia el sur con uso residencial, a partir de asentamientos informales sobre el ERG. La inmigración desbordó la capacidad habitacional y frente a eso se produjo una rápida ocupación espontánea del espacio, que al final de la etapa involucró también la Margen Sur. A partir de entonces, la denominación "Margen Sur" será extensiva a todo el sector urbano situado al sur del estuario. Ante la falta de alternativas, los asentamientos informales se localizaron sobre humedales sin servicios básicos e infraestructura. En 1991 la superficie urbana alcanzó 1.209 ha, o sea aumentó el 157 \%, a 38,9 ha/año.

En 1991-2001 la mancha urbana se expandió hacia el norte, completando el sector residencial de vivienda colectiva contiguo al aeropuerto. En Margen Sur el crecimiento se debió al desarrollo de emprendimientos productivos. El área urbana alcanzó a 1.581 ha, aumentando $30,8 \%$ a un promedio de $37,2 \mathrm{ha} /$ año. Es la fase de menor desarrollo urbano absoluto y relativo, por disminución de la actividad industrial. Sin embargo, los índices continuaron altos (Tabla 6), comparativamente con otras ciudades argentinas. Durante los dos períodos descriptos la urbanización se extendió sin que hubiese un instrumento de planificación para ello.

En 2001-2020 la re-industrialización indujo un incremento de la expansión del 83 \% respecto de 2001. Hacia el norte predominó la lógica privada de desarrollo y hacia el oeste urbanizaciones privadas y estatales, estas últimas generadas hasta 2010. Hacia el sur, la ciudad creció en base a la producción informal de viviendas. Como ocurriera en el período inicial, estas tierras poco aptas para habitar fueron la única posibilidad de ocupación por la nueva población, sin acceso a un mercado en el que predominaba la especulación inmobiliaria. La Figura 4 muestra vacíos urbanos correspondientes a granjas de dominio privado aún no urbanizadas.

El Plan de Desarrollo Territorial de 2011 aportó al ordenamiento, aunque a destiempo, ya que la ciudad había crecido atravesando una grave situación coyuntural en materia de vivienda. Incluye una serie de líneas estratégicas: una de crecimiento hacia el norte y oeste, y otra ambiental que define un conjunto de parques, o Reservas Naturales Urbanas. 
Figura 4. Expansión urbana de Río Grande. Período 1972- 2020.
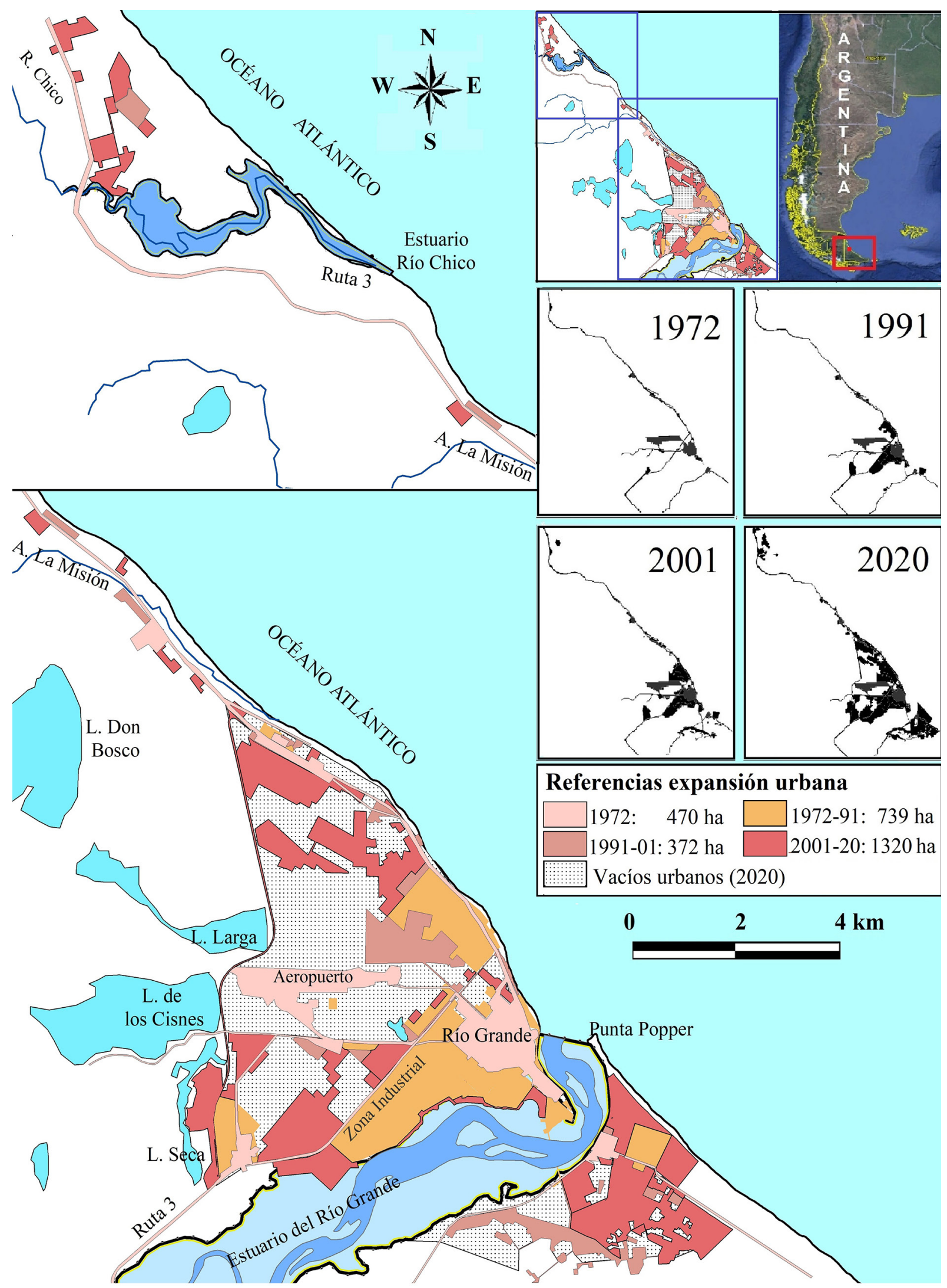

Elaboración propia 
Tabla 6. Expansión urbana de Río Grande. Período 1972-2020

\begin{tabular}{|c|c|c|c|c|}
\hline Año & Superficie total [ha] & $\begin{array}{c}\text { Superficie de ex- } \\
\text { pansión [ha] }\end{array}$ & $\begin{array}{c}\text { Crecimiento medio } \\
\text { anual en el período } \\
{[\text { ha año] }}\end{array}$ & $\begin{array}{c}\text { Tasa de incremento } \\
\text { anual [\%] }\end{array}$ \\
\hline 1972 & 470 & & & \\
\hline 1991 & 1.209 & 739 & 38,9 & 5,10 \\
\hline 2001 & 1.581 & 372 & 37,2 & 2,72 \\
\hline 2020 & 2.901 & 1.320 & 69,5 & 3,25 \\
\hline
\end{tabular}

Elaboración propia

\subsubsection{Evolución del cambio de cobertura del Suelo (CCS)}

La expansión urbana, analizada en términos urbanísticos, implica cambio de cobertura y pérdida de superficie de los humedales incluidos, pero existen otras intervenciones que generan cambios con desaparición de superficie de estos ecosistemas, tales como movimiento de suelos preparatorio para futuras urbanizaciones, apertura de calles en ejecución, canteras de áridos, basurales y otras afectaciones en zonas aun no consolidadas como área urbana.

El CCS, que alcanza a 3.554 ha (Tabla 7, Figura 5), excede significativamente a la superficie de expansión según se muestra en Tabla 8. El período 2020 ha sido el de mayor impacto nominal, afectando en promedio 93,3 ha/año de suelos que no eran urbanos. El mayor crecimiento relativo correspondió al período inicial, con una tasa del 5,24\% anual.

La extracción de áridos ha intervenido 224 ha entre 1972 y 2020, que incluyen 125 ha de canteras existentes, activas o no, y 99 ha de áreas ya urbanizadas y predios que se utilizaron informalmente con tal fin para construcción de obras de infraestructura. Estimando un espesor medio de 2 m de excavación, resulta un volumen total de $4.480 .000 \mathrm{~m}^{3}$.

Tabla 7. Evolución del cambio de cobertura del suelo por expansión urbana

\begin{tabular}{|c|c|c|c|c|c|c|}
\hline \multirow{2}{*}{ Período } & \multicolumn{4}{|c|}{ CCS [ha] } & \multirow{2}{*}{$\begin{array}{c}\begin{array}{c}\text { Crecimiento } \\
\text { medio anual }\end{array} \\
{\left[\mathrm{ha} \mathrm{a}^{-1}\right]}\end{array}$} & \multirow{2}{*}{$\begin{array}{c}\text { Tasa increm } \\
\text { anual }\end{array}$} \\
\hline & Zona N & Zona S & Total & Acum & & \\
\hline 1972 & 459 & 31 & 490 & 490 & - & - \\
\hline 1972-1991 & 728 & 74 & 802 & 1.292 & 42,2 & 5,24 \\
\hline 1991-2001 & 323 & 167 & 490 & 1.782 & 49,0 & 3,28 \\
\hline $2001-2020$ & 1.297 & 476 & 1.772 & 3.554 & 93,3 & 3,71 \\
\hline Total & 2.807 & 747 & 3.554 & & 63,8 & 4,21 \\
\hline
\end{tabular}

Elaboración propia

\subsubsection{Vacíos urbanos sin cambio de cobertura del suelo}

Estos espacios, total o parcialmente aislados por estructuras físicas urbanas, mantienen la cobertura, pero cambian en su hidrología y geomorfología, con potencial afectación de humedales que pudieran incluir. En materia de biodiversidad, la pervivencia de las especies que ocupan sectores adyacentes a una reciente urbanización puede verse amenazada por reducción del hábitat disponible y por la pérdida de calidad para sostenerlas (Balfors, Mörtberg \& Gontier, 2005); las áreas impermeables adyacentes alteran el ciclo hidrológico local y zonal, en magnitud y temporalidad de la escorrentía (Marshall \& Shortle, 2004) y la reducción de infiltración produce el descenso del nivel freático en las vegas y así su degradación.

Tabla 8. Superficies de expansión urbana y de áreas adicionalmente afectadas en 2020

\begin{tabular}{|c|c|c|}
\hline Expansión urbana 2020 & CCS adicional al área de expansión & $\begin{array}{c}\text { Vacíos urbanos que implican aisla- } \\
\text { miento y fragmentación }\end{array}$ \\
\hline $2.901 \mathrm{ha}$ & $653 \mathrm{ha}(+22,5 \%)$ & $1.232 \mathrm{ha}(+42,5 \%)$ \\
\hline
\end{tabular}

Elaboración propia 
Figura 5. Los humedales en 1972 (A) y la evolución del cambio de cobertura del suelo (B).
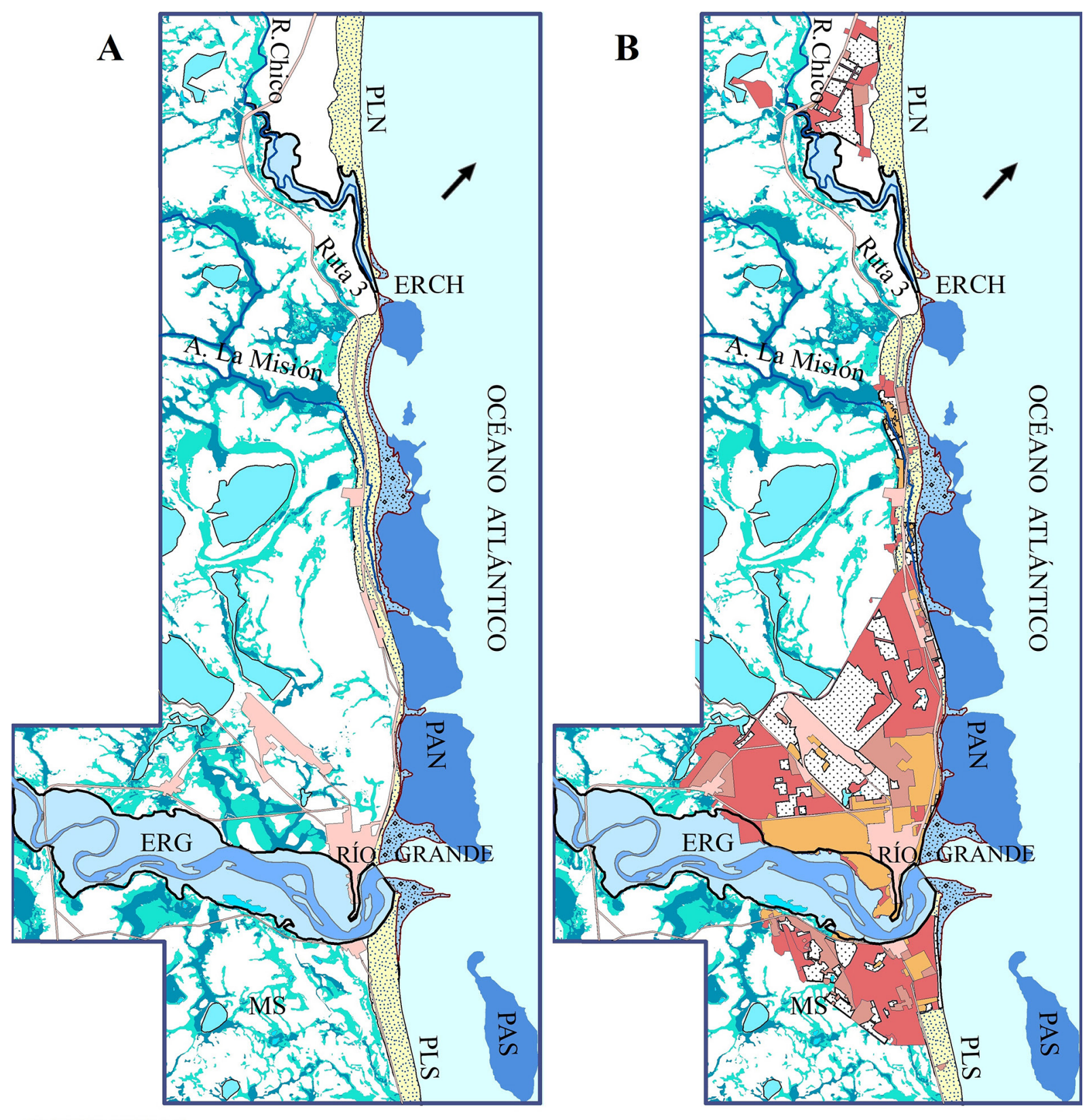

REFERENCIAS

\begin{tabular}{|c|c|c|c|}
\hline Humed & dales & & Cambio de cobertura de suelo \\
\hline & Estuario & Vega subhúmeda & 1972 \\
\hline 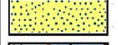 & Playa de grava y arena & Vega húmeda & 1991 \\
\hline 6. & AS: Playa bajo aguas someras & Laguna & 2001 \\
\hline 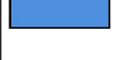 & Plataforma de abrasión & & 2020 \\
\hline Abrevi & aturas & & Vacíos urbanos (2020) \\
\hline ERG & Estuario del río Grande & & \\
\hline $\begin{array}{l}\mathrm{ERCH} \\
\mathrm{P} \triangle \mathrm{N} / \mathrm{S}\end{array}$ & Estuario del río Chico & & Escala gráfica \\
\hline $\mathrm{PLN} / \mathrm{S}$ & $\begin{array}{l}\text { Playa norte/sur } \\
\text { Plor }\end{array}$ & & $\begin{array}{lll}0 & 2 & 4 \mathrm{~km} \\
\end{array}$ \\
\hline
\end{tabular}

Elaboración propia 


\subsection{Evolución de afectación de humedales por consecuencia del crecimiento urbano}

La ciudad se extendió sobre espacios de comunidades de estepa y humedales del ambiente rural, alterando vegas, playas y el ERG. La afectación fue de 1.281 ha por cambios directos y 407 ha por fragmentación, totalizando 1688 ha de humedales (Figura 6), correspondiendo la mayor proporción a vegas (Figura 7). La capa de pérdida de humedales por período resultó de la intersección de la capa delimitada para 1972 (Figura 5-A) con la de CCS (Figura 5-B). Las magnitudes resultantes se indican en Tabla 9, así como las superficies áridas del medio rural incorporado al espacio urbano. Las áreas de zonas húmedas fragmentadas y aisladas, remanentes en vacíos urbanos se suman a las alteraciones, que la Tabla 9 muestra en términos absolutos y relativos, respecto de la extensión original de humedales indicada en Tabla 5. La afectación de playas alcanza al 42 \% de la superficie, (29 \% CCS y $13 \%$ fragmentación) pero crece al 82\% en los $17 \mathrm{~km}$ de costa entre La Misión y el fin de la urbanización en la zona sur (entre ** en Figura 6). Éstas han perdido sus funciones esenciales: sustento de cadenas tróficas y hábitat de singular biodiversidad que incluye especies amenazadas. Su hidrología fue alterada, y perdieron su aptitud escénica y recreativa, así como su valor como patrimonio cultural. Todo ello justifica considerar su pérdida como humedal.

El avance de asentamientos informales sobre el ERG se consolidó a partir de rellenos con diversos materiales, incluso residuos sólidos urbanos. El área total afectada involucra menos del $10 \%$ del estuario, lo que comparativamente puede interpretarse como un impacto leve, sin embargo es importante la pérdida de marismas marginales de Sarcocornia spp.

Se calculó un volumen total de 3,075.000 $\mathrm{m}^{3}$ de áridos utilizado en las zonas húmedas bajas intervenidas. Para ello se consideró un espesor medio de relleno de $0,30 \mathrm{~m}$, aplicable al $80 \%$ de 1.281 ha de humedales intervenidos (un $20 \%$ del área no ha sido acondicionada aún).

En 1972-1991 la ciudad avanzó sobre 413 ha de estos ecosistemas, o sea el 51 \% del CCS, siguiendo la distribución espacial descripta en el análisis de la expansión urbana, con predominio de la ocupación de vegas, como sucederá en todos los períodos. Se produjo una importante ocupación informal sobre el estuario (más de la mitad del impacto en el mismo ocurrió en este período) y pérdida de playas por consolidación de barrios urbanos costeros y por minería de áridos.

Las políticas desfavorables a la promoción industrial en Tierra del Fuego en el período 1991-2001, que concluyó con una de las peores crisis económicas de Argentina, redujeron el crecimiento y la presión sobre los humedales (Figura 8 y Tabla 10). No obstante, persistieron altos índices de expansión, debido al déficit de viviendas remanente del período anterior. El avance sobre el ERG siguió a ritmo levemente inferior; la pérdida de superficie de vegas correspondió en un 41 \% a la Margen Sur, en donde se adjudicaron tierras para producción, y la alteración de playas se redujo en intensidad, de 7,1 a 4,2 ha/año.

La participación de zonas húmedas en el cambio de suelo rural a suelo urbano disminuyó del 51,5 \% al 33,3\%; por la construcción de complejos de viviendas en tierras altas.

Tras la reactivación industrial que siguió a la crisis de 2001, el nuevo pulso expansivo de Río Grande incrementó el CCS en el último período de análisis. El 35,1 \% de los cambios correspondió a humedales (623 ha). La fragmentación de estos ecosistemas en 2020 era de 407 ha, de las cuales 301 ha se consideran de carácter severo.

Una fuerte intervención en la zona oeste, implicó fraccionamiento y apertura de calles, pero sin que se completase su urbanización. Paralelamente, extensiones de vegas anegadizas de la Margen Sur fueron objeto de ocupación informal. El avance sobre el estuario se desaceleró, en parte por la demarcación de la línea de ribera que delimita el dominio público por la DGRH.

La plataforma de abrasión, las playas de aguas someras y el ERCH no experimentaron cambios físicos, ni tampoco las lagunas, excepto las propias del ambiente de vegas, consideradas parte de estos ecosistemas. 
Figura 6. Humedales afectados por el crecimiento urbano

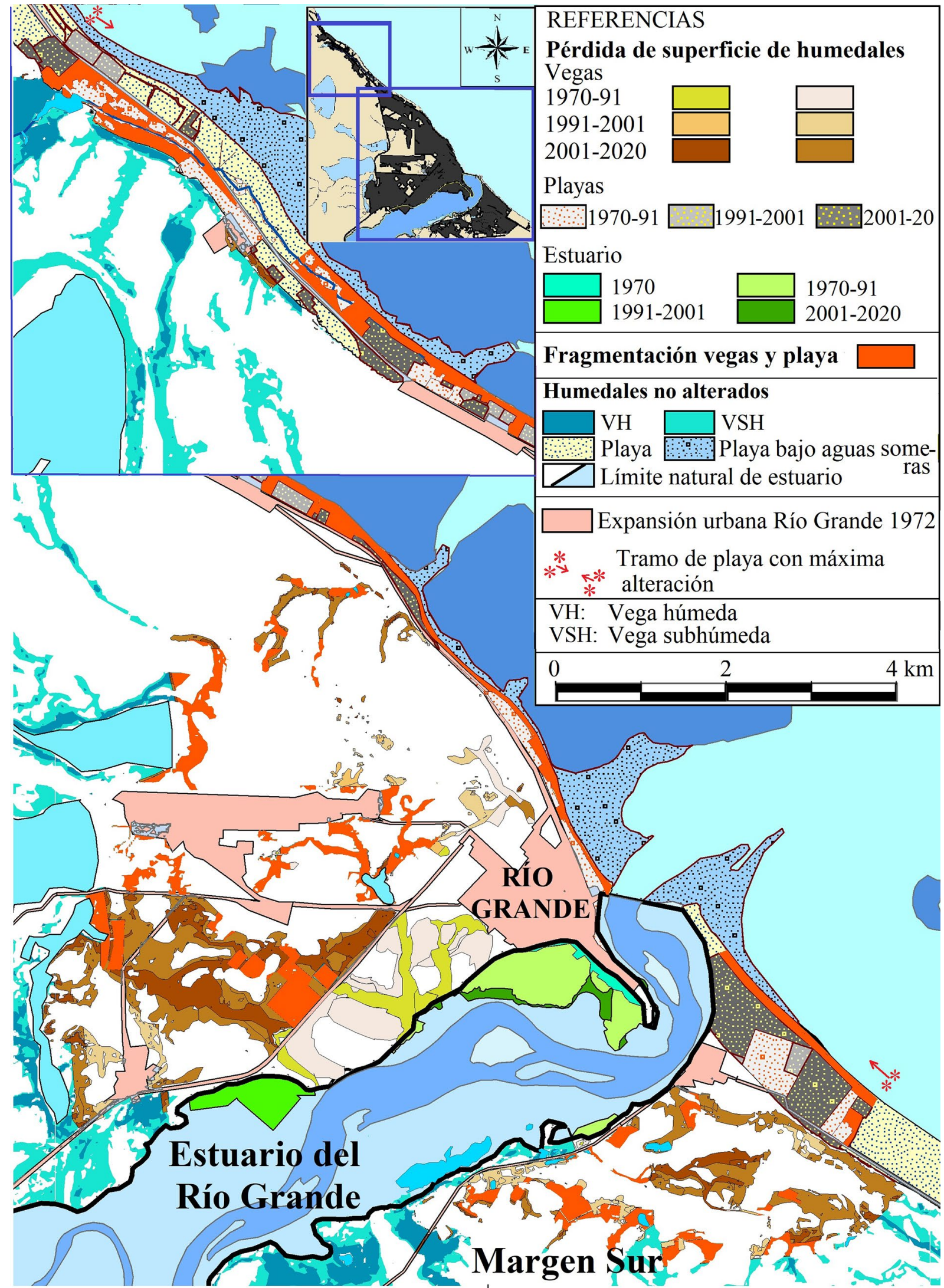

Elaboración propia 
Tabla 9. Pérdida de superficie de humedales y fragmentación

\begin{tabular}{|c|c|c|c|c|c|c|c|c|c|c|c|}
\hline \multirow[t]{2}{*}{ Humedal } & \multirow[t]{2}{*}{ Zona } & \multicolumn{5}{|c|}{ Pérdida de superficie por período [ha] } & \multicolumn{3}{|c|}{$\begin{array}{l}\text { Humedales fragmentados } \\
\text { /aislados 2020)[ha] }\end{array}$} & \multirow{2}{*}{$\begin{array}{c}\text { Área tot. } \\
\text { afectada } \\
\text { [ha] }\end{array}$} & \multirow{2}{*}{$\begin{array}{c}\text { Área afecta- } \\
\text { da respecto } \\
1972[\%]\end{array}$} \\
\hline & & 1972 & $1972-91$ & 1991-01 & $2001-20$ & Total & Severo & Moderado & Total & & \\
\hline Estuario RG & & 19 & 99 & 41 & 19 & 178 & & & & 178 & 9,3 \\
\hline \multirow{3}{*}{ Playas } & $\mathrm{N}$ & 27 & 95 & 31 & 76 & 229 & 144 & 0 & 144 & 373 & 38,3 \\
\hline & S & 7 & 40 & 11 & 102 & 160 & 27 & 0 & 27 & 187 & 53,7 \\
\hline & Tot & 34 & 135 & 42 & 178 & 389 & 171 & 0 & 171 & 560 & 42,3 \\
\hline \multirow{3}{*}{$\begin{array}{l}\text { Vegas sub } \\
\text { húmedas }\end{array}$} & $\mathrm{N}$ & 17 & 116 & 39 & 186 & 359 & 47 & 43 & 90 & 449 & 24,3 \\
\hline & S & 2 & 1 & 28 & 103 & 135 & 46 & 8 & 54 & 188 & 25,2 \\
\hline & Tot & 19 & 117 & 68 & 289 & 493 & 93 & 51 & 144 & 637 & 24,5 \\
\hline \multirow{3}{*}{$\begin{array}{l}\text { Vegas } \\
\text { húmedas }\end{array}$} & $\mathrm{N}$ & 9 & 62 & 8 & 111 & 190 & 26 & 54 & 80 & 270 & 21,4 \\
\hline & S & 1 & 0 & 5 & 25 & 31 & 12 & 0 & 12 & 43 & 8,6 \\
\hline & Tot & 10 & 62 & 13 & 136 & 221 & 38 & 54 & 92 & 313 & 17,8 \\
\hline \multicolumn{2}{|l|}{ Total Vegas } & 29 & 179 & 80 & 426 & 714 & 130 & 106 & 236 & 950 & 21,8 \\
\hline \multicolumn{2}{|c|}{ Total humedales } & 82 & 413 & 163 & 623 & 1.281 & 302 & 105 & 407 & 1.688 & \\
\hline \multicolumn{2}{|l|}{$\mathrm{AASH}^{(1)}$} & 408 & 389 & 326 & 1150 & 2.426 & & & & & \\
\hline \multicolumn{2}{|l|}{ Área total } & 490 & 802 & 489 & 1.773 & 3.554 & & & & & \\
\hline
\end{tabular}

(1) Áreas afectadas sin humedales.

Elaboración propia

Figura 7. Superficie de humedales afectados. A: por tipo de humedal en relación al CCS total. B: Composición de la afectación en relación a totales alterados. Situación a 2020
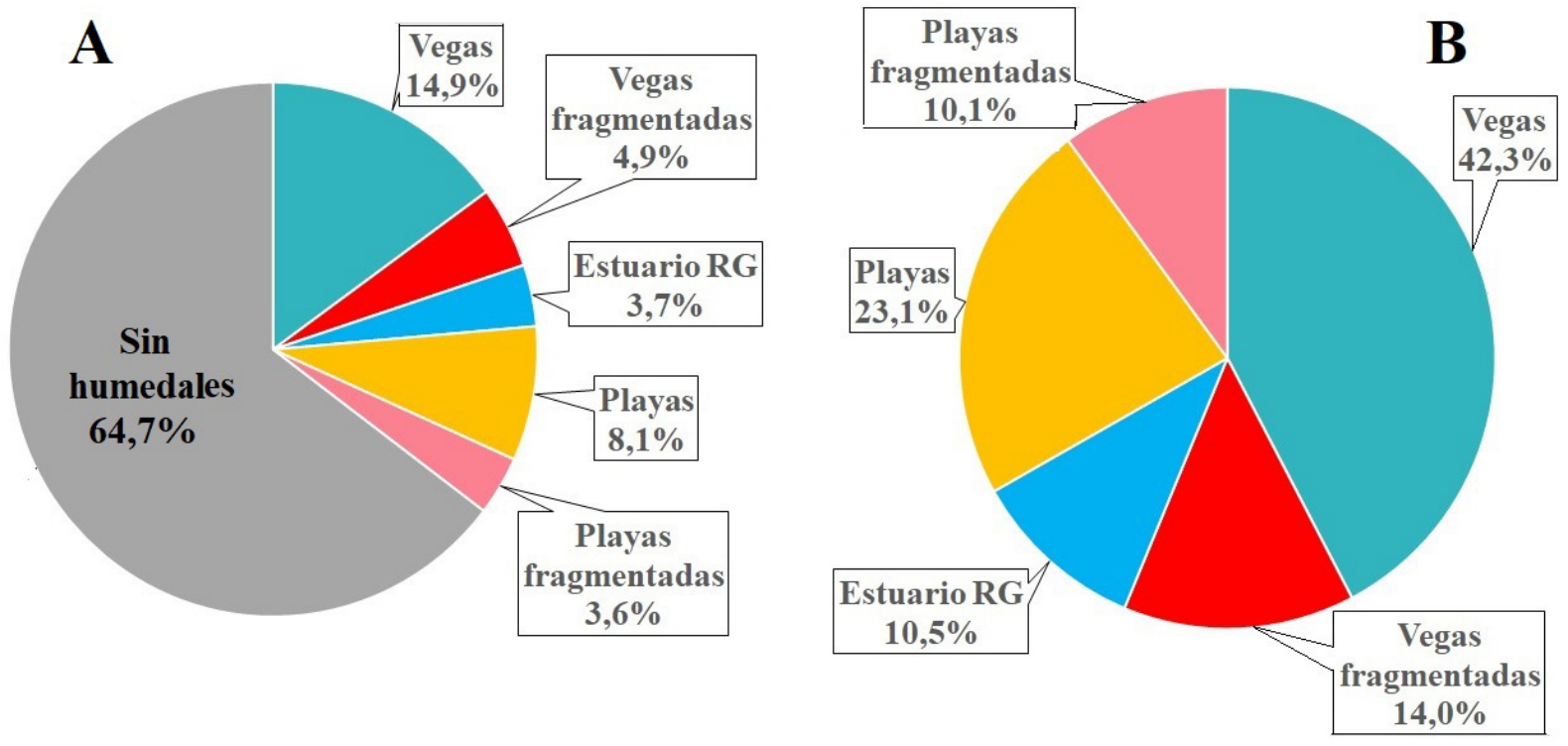

Elaboración propia 
Figura 8. Pérdida anual de superficie de humedales por período y tipo de humedal y su proporción relativa al cambio de suelo total

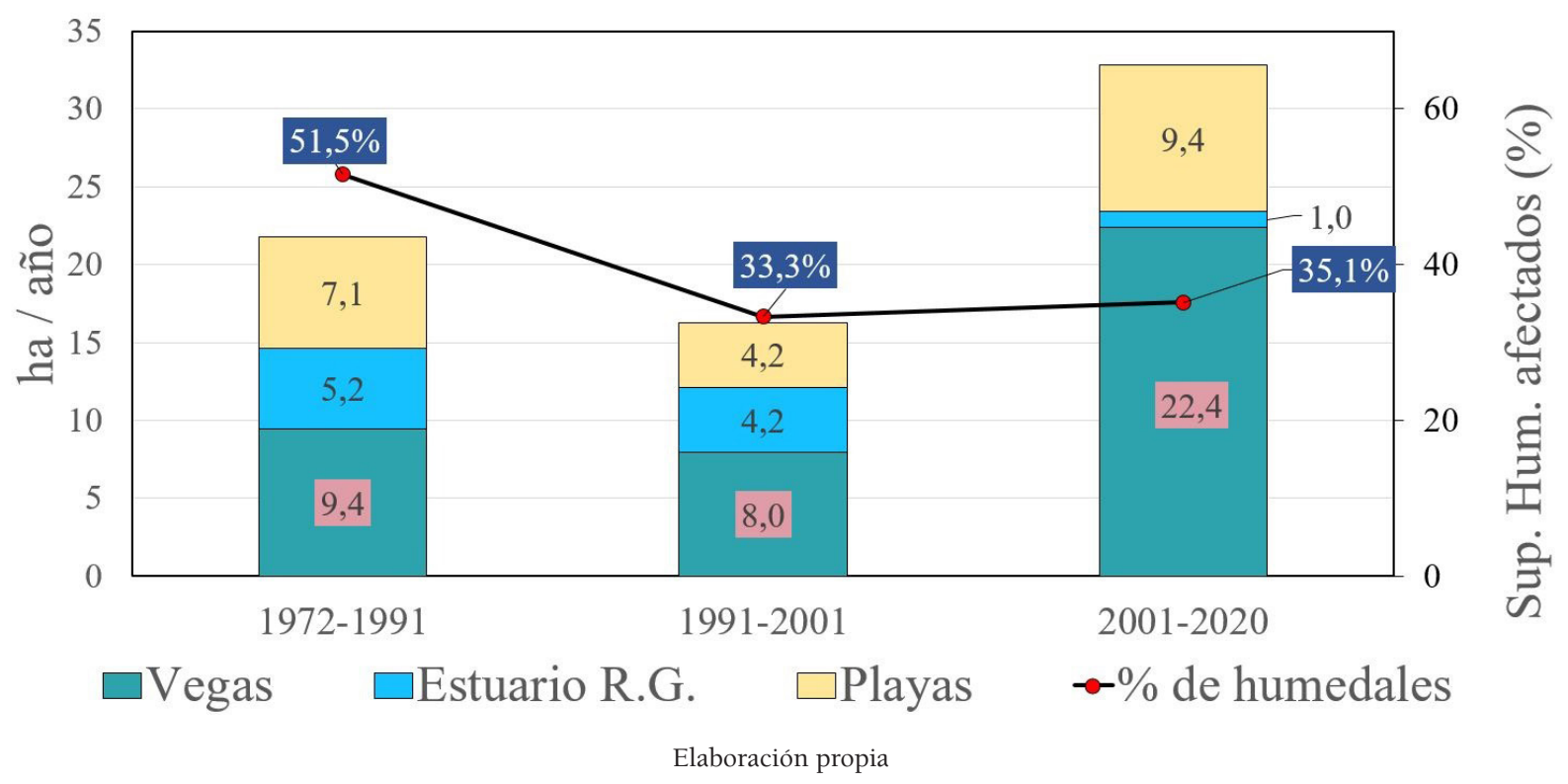

\subsection{Cambios en los sistemas hídricos}

Ha sido descrito el efecto general de la urbanización sobre la hidrología superficial y subterránea, especialmente en relación a vacíos urbanos con remanentes de humedales. Se consideran a continuación situaciones particulares de alteración de los sistemas hídricos.

Terraplenes de obras viales han condicionado la dinámica hidrológica, (Figura 9-A). La ruta $\mathrm{n}^{\circ} 3$, en su trayecto urbano obstruyó el flujo procedente del oeste en la vega, generando acumulación de humedad y dificultando su posterior urbanización (Figura 9-B).

Figura 9. A: Vega húmeda en la Margen Sur del Río Grande donde se aprecia el contraste en el humedal, aguas arriba y abajo del camino. B: similar situación, en mayor magnitud
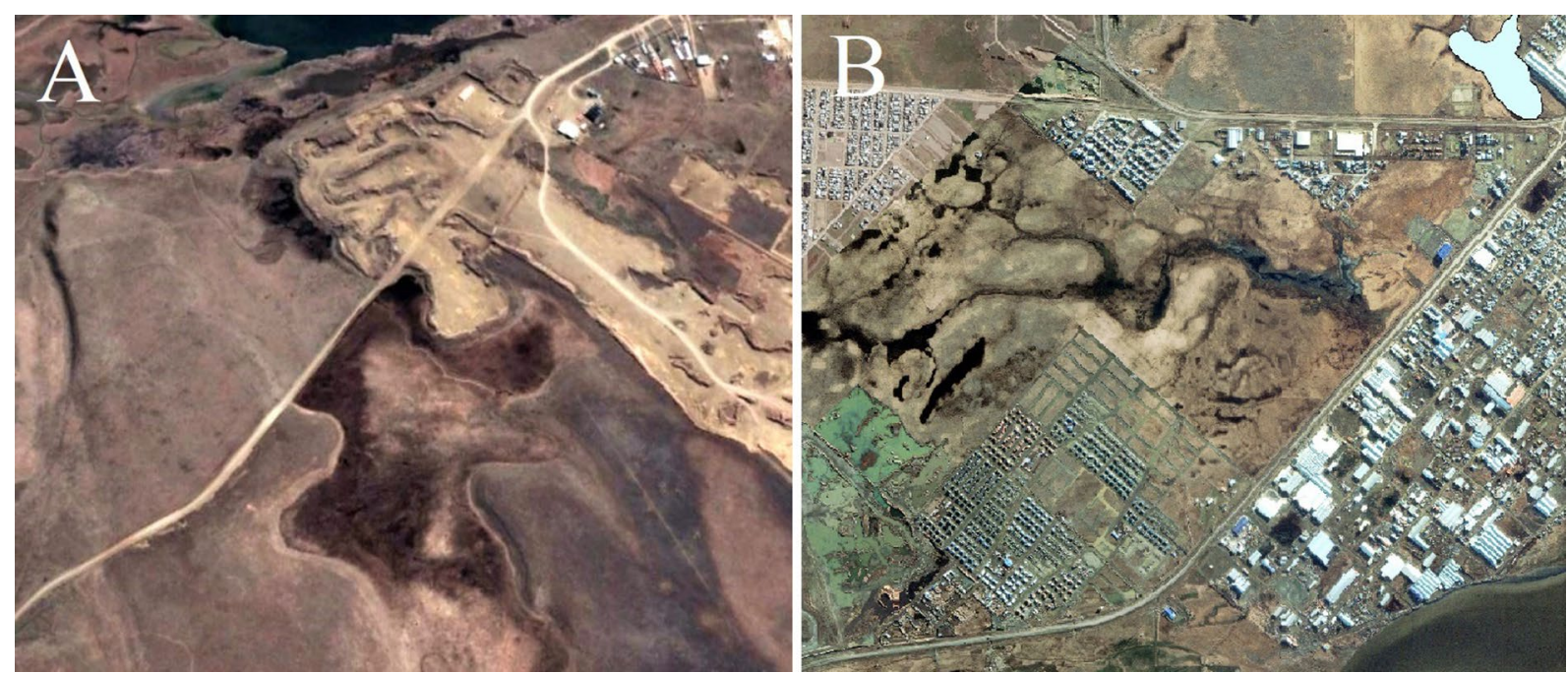

Fuente: Google Earth, 2006

La urbanización de vegas implicó pérdida de los sistemas de drenaje vinculados, así como pequeñas lagunas de este ambiente. Vera (2019) describe la ocupación informal de más de 100 ha en Margen Sur, obstruyendo cursos temporarios que drenaban excedentes hídricos. Esto ocurrió sin que se construyeran los desagües pluviales que deberían suplir la función de drenaje que estos cursos cumplían, resultando el 
sostenido anegamiento de las zonas ocupadas. Otro caso es el desvío del arroyo que desaguaba la laguna Los Patos, mediante un canal adyacente a la ruta $\mathrm{n}^{\circ} 3$ y la anulación de su cauce original. Así desaparecieron con la urbanización cursos intermitentes que evacuaban excedentes hídricos de la actual zona céntrica. La función hidrológica que cumplían fue luego suplida por el sistema de desagües pluviales, con incremento de superficies impermeables, en desmedro de la recarga de aguas subterráneas e implicando pérdida de hábitat.

Vegas y turberas suelen ser drenadas para favorecer el ingreso del ganado para pastoreo, habilitar predios para agricultura y mejorar el tránsito. Estos cambios afectaron la hidrología, produciendo reducción de la capacidad de regulación y degradación por descenso del nivel freático, como ocurrió en la turbera de la Misión y en áreas periurbanas de Margen Sur.

\section{Discusión}

\subsection{Identificación delimitación y clasificación de humedales}

El uso de un enfoque jerárquico para la clasificación de humedales como el sistema Ramsar permite una identificación rápida de los mismos y facilita su caracterización. Si bien superpone criterios de vegetación, suelo, inundación y formas del terreno (Semeniuk \& Semeniuk, 1997), se ajusta a los objetivos del trabajo y es adecuado para el análisis a escala urbana. Otros sistemas de clasificación, como los utilizados en el Inventario Nacional de Humedales de Estados Unidos (Cowardin, 1979; Cowardin \& Golet, 1995; Federal Geographic Data Comitte, 2013) y el sistema MedWet (Farinha et al., 2005) en la región mediterránea, requieren de una descripción de hábitats de mayor nivel de detalle (Kandus \& Minotti, 2018). Por otra parte, la agrupación en clases HGM, tomando en cuenta geoformas y régimen hidrológico, contribuye a la comprensión de funciones y a la demostración de cómo se vinculan con los bienes y servicios utilizados por la sociedad (Brinson, 2004). Si bien HGM se reconoce como un enfoque que provee un marco para la evaluación, más que un sistema de clasificación (Tiner, 2017), resulta apropiado para su caracterización funcional.

Hay pocos lugares en la estepa Patagónica con la diversidad, distribución y extensión de zonas húmedas presentes en las cercanías de la ciudad de Río Grande. A los estuarios y otros humedales costeros se agregan los continentales, que cubren 1/3 del área terrestre de referencia, el $27 \%$ de vegas. Estos índices exceden promedios regionales. Collantes et al. (2009) consideran 5 al 20\% de cobertura en la estepa fueguina, en tanto que Gandullo, Peña, \& Campo (2006) estiman un 4\% de mallines (vegas) en la Patagonia extra-andina.

\subsection{Expansión urbana y cambio de la cobertura del suelo}

El análisis espacial se facilitó por el contraste propio de las urbanizaciones y por inexistencia, de la típica gradación urbano-rural en anillos concéntricos que señalan urbanistas como García Ramón, Tullas Pujol \& Valdovinos Perdices (1995) y Cardoso \& Fritschy (2012).

El buen ajuste de la correlación entre el CCS y la expansión urbana se aprecia en la Figura 10. La ecuación de la recta de regresión indica que el CCS tiende a superar en un 27 \% a la expansión urbana en términos acumulativos. Los resultados muestran, en concordancia con Weber \& Piuissant (2003), que la urbanización causa cambios en la cobertura del suelo que pueden llevar a profundas transformaciones sociales, económicas y ambientales", lo cual refuerza la importancia de considerar de manera integral ambos fenómenos (vinculando expansión y CCS) en las políticas urbanas orientadas al crecimiento poblacional.

El particular crecimiento de la ciudad se dio sujeto a condicionamientos que limitaron la producción formal de suelo urbano y dieron lugar a asentamientos informales. Uno de ellos fue la propiedad privada de estancias y granjas que dominaron el espacio circundante junto con la escasa voluntad de venta de sus propietarios. En otro aspecto, Tierra del Fuego no fue hasta 1991 una provincia, sino un territorio nacional, dependiente del Gobierno Central. Otro obstáculo para un desarrollo ordenado fue el reiterado desfase entre la formulación de los planes de ordenamiento urbano y la efectiva aprobación, que motivó que casi regularmente la ciudad evolucionara de manera muy diferente a la prevista. El último Plan, vigente desde 2011, aunque incluye en un programa ambiental la protección y puesta en valor de "cintas costeras" así como de Punta Popper y laguna los Patos, carece de una perspectiva ecosistémica, y su texto 
omite la mención del término "humedales". Esto reafirma la necesidad, expresada por Moreno-Casasola et al., (2019), del reconocimiento y valoración institucional de estos ecosistemas en las políticas públicas, como base para su gobernanza.

Figura 10. Cambio de la cobertura del suelo como función de la expansión urbana

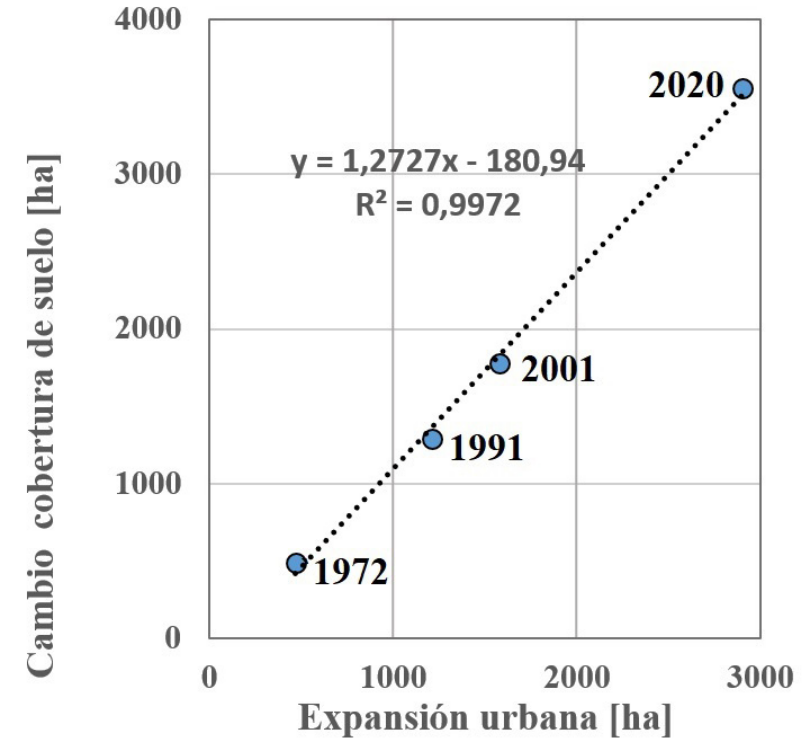

Elaboración propia

\subsection{Afectación de humedales}

La mayor pérdida de superficie de humedales corresponde a vegas; sin embargo, la situación más crítica es la de las playas, ocupadas por urbanizaciones, espacios públicos, viaducto costanero, etc. La extracción de áridos en la costa marítima ha sido una causa sustancial de la degradación de la costa, por la falta de reposición natural y la pérdida de hábitat de singular biodiversidad. La explotación de este material en la costa urbana, naturalmente erosiva, sin previsión de los efectos ambientales negativos, ha sido un factor determinante para que la situación ambiental de la Reserva Costa Atlántica en dicho sector sea gravísima.

Situaciones similares se dan a nivel global. Gallagher \& Pedruzzi (2019) expresan que la constante urbanización y el desarrollo de la infraestructura han triplicado la demanda de áridos en los últimos 20 años y que la extracción en áreas costeras lleva a la erosión acelerada de las playas. En relación al manejo del problema, la experiencia europea presenta casos ilustrativos de su complejidad. Ante la alarmante desaparición de humedales costeros de Europa, intensificada en la segunda mitad del siglo XX, sobre todo en el Mediterráneo, por el desarrollo urbano turístico e industrial (Airoldi \& Beck, 2007), emergieron políticas y regulaciones para su conservación y uso racional. La extracción de más de 17 millones de $\mathrm{m}^{3}$ de arena en la costa de las provincias españolas de Castellón, Valencia y Alicante durante tres décadas a partir de 1956 para agricultura intensiva (Viciana Martínez-Lage, 1999) generó un grave deterioro ambiental y colisionó luego con el desarrollo turístico. Fue necesaria una gran inversión para restaurar las playas, mediante incorporación de arena y escollerado. La ley de costas de 1988 (Boletín Oficial del Estado, 1988) aplicó severas restricciones a la extracción costera y en 2010 se estableció un instructivo ambiental específico para los proyectos de extracción de arena marina (Gobierno de España, 2010). Sin embargo, como señalan Mirailles García et al. (2012), notables cambios, avalados por los planes de desarrollo, volvieron a alterar el ambiente costero natural para la construcción edilicia, que por la crisis de 2008, en muchos casos no se concretó.

Análogamente, en Río Grande, a raíz de una demanda particular, la Justicia ordenó en 2017 la prohibición de la extracción de áridos en la Reserva Costa Atlántica, en consecuencia con lo que establece su Plan de Manejo. El fallo fue cumplido, pero se permite el uso de la playa para acopio de material por parte de las empresas ya instaladas, lo que mantiene los efectos negativos e imposibilita su restauración. Ambos 
casos evidencian que medidas enfocadas sectorialmente no bastan para garantizar un manejo sostenible, requiriéndose un plexo articulado de planificación, normativa y control, así como coordinación entre organismos que toman decisiones sobre humedales.

En relación a los del tipo continental, éstos constituyen un patrimonio social en materia de bienes y servicios ambientales, sin embargo es baja su aptitud como espacios urbanizables, más cuando su ocupación es de carácter informal, con carencias de servicios de agua y saneamiento que determinan vulnerabilidad social. En ciudades de América Latina, la ocupación irregular del espacio suele darse como instancia previa a su posterior consolidación en el tejido urbano (Clichevsky, 2006). Esto ocurrió con las ocupaciones de Río Grande, con la particularidad de que fueron consecuencia de intensas migraciones y no estuvieron ligadas a la pobreza, como es usual, sino a la falta de viviendas para satisfacer la demanda de trabajadores.

Las áreas de humedales son objeto frecuente de asentamientos informales (Clichevsky, 2006), dada su disponibilidad y su usual pertenencia al dominio público. Además de las consecuencias ambientales directas, estas prácticas implican alta demanda de áridos para elevar el nivel natural del suelo, cuya dimensión no suele ser prevista. En Río Grande, el volumen de material requerido para elevar el nivel de las zonas húmedas deprimidas $\left(3.075 .000 \mathrm{~m}^{3}\right)$, representa el $69 \%$ de la producción total de las canteras desde $1972\left(4.480 .000 \mathrm{~m}^{3}\right.$ ). Considerando el empleo adicional de escombros, residuos sólidos urbanos, etc., el uso de áridos para este fin significa alrededor del 60 \% del total extraído entre 1972 y 2020. La necesidad de elevar el nivel del terreno en zonas húmedas explica la proliferación de sitios extractivos. El caso de estudio evidencia que la ocupación de humedales urbanos puede inducir pérdidas adicionales de éstos por minería de áridos. Recomendaciones para el uso de este recurso en diferentes regiones del mundo no advierten sobre la alta demanda que implica acondicionar zonas húmedas y se desconocen los volúmenes destinados a tal fin. Los estudios sobre efectos de pérdida de estos ecosistemas por expansión urbana tampoco consideran el impacto en las reservas de grava y arena, particularmente escasas en países desarrollados. Por lo expuesto, corresponde señalar la pertinencia de relacionar el estudio de ambos problemas.

En coincidencia con conclusiones de Lee et al. (2006) sobre impactos de urbanizaciones en humedales costeros de Australia, se observa que los movimientos de suelo para nueva infraestructura urbana generan cambios directos sobre las áreas intervenidas, e indirectos en zonas adyacentes, alterando su geomorfología e hidrología. En vegas, tal fragmentación es irreversible, sobre todo en unidades pequeñas, irrecuperables como hábitat, por la imposibilidad de ser reestablecidas sus conexiones. Hooftman, Schmid \& Diemer (2004) sostienen que uno de los principales objetivos de conservación debería ser mitigar la fragmentación de hábitats naturales en orden de sostener poblaciones de especies. Sin embargo, el problema adquiere complejidad en procesos de crecimiento urbano acelerado, en donde las ocupaciones informales y la coyuntura habitacional reducen las alternativas de expansión.

En el caso de estudio, no existiendo áreas buffer, el alto nivel de fragmentación de hábitats de playa es incompatible con la pervivencia de las aves playeras. Sin embargo, en contraste con las vegas, muchos tramos costeros podrían ser restaurados mediante acciones adecuadas. Ello depende en gran medida del uso del suelo (Ehrenfeld, 2000). Sería entonces criterioso reconvertir el uso de la costa urbana hacia actividades de bajo impacto, como recreación y turismo, en el marco del Plan de Manejo de la Reserva Costa Atlántica.

El análisis temporal verifica, como era esperable, correspondencia entre el avance de la urbanización y la desaparición de zonas húmedas. La Tabla 10 permite comparar la evolución de los distintos índices resultantes. Las tasas anuales relativas de crecimiento de CCS y de pérdida de humedales superaron siempre a las de expansión urbana, con diferencias más significativas en los períodos con impulso industrial. El CCS, directamente relacionado con pérdida de estos ecosistemas, resulta de una intervención rápida y preparatoria para la urbanización, la cual requiere de mayor tiempo en consolidarse.

Surge del análisis del caso que ante un período de promoción de la industria con generación de alta demanda habitacional, seguido por otro recesivo, parte del CCS producido en el primero se transforma en desarrollo urbano en el segundo. En este último, la expansión crece "inercialmente" en espacios previamente acondicionados y disminuye la intervención en nuevos espacios rurales, así como las urgencias que motivan asentamientos informales en humedales. Nuevas medidas reimpulsando el desarrollo industrial reproducen otro ciclo similar. Estas respuestas a políticas de desarrollo oscilantes pueden ser replicables en ciudades de países emergentes, pero en un contexto en el que el Estado tenga cierta capacidad de respuesta en materia de producción de espacio urbano, y la población disponga de recursos que le permitan el acceso a la vivienda. 
Tabla 10. Comparación de índices anuales incrementales en materia de expansión urbana, cambio de cobertura de suelo y pérdida de humedales

\begin{tabular}{|c|c|c|c|c|c|c|}
\hline & \multicolumn{3}{|c|}{ Incremento anual medio [ha/año] } & \multicolumn{2}{c|}{ Tasa de crecimiento anual [\%] } \\
\hline Período & $\begin{array}{c}\text { Expansión } \\
\text { urbana }\end{array}$ & CCS & $\begin{array}{c}\text { Pérdida de } \\
\text { humedales }\end{array}$ & $\begin{array}{c}\text { Expansión } \\
\text { urbana }\end{array}$ & CCS & $\begin{array}{c}\text { Pérdida de } \\
\text { humedales }\end{array}$ \\
\hline $1972-1991$ & 38,9 & 42,2 & 21,8 & 5,10 & 5,24 & 9,95 \\
\hline $1991-2001$ & 37,2 & 49 & 16,3 & 2,72 & 3,28 & 2,96 \\
\hline $2001-2020$ & 69,5 & 93,3 & 32,8 & 3,25 & 3,71 & 3,63 \\
\hline $1972-2020$ & 50,6 & 63,8 & 25,0 & 3,86 & 4,21 & 5,90 \\
\hline
\end{tabular}

Elaboración propia

Se observa la importancia de implementar a nivel nacional y regional un sistema de información integral estandarizada sobre el cambio espacial y temporal de cobertura y usos del suelo, semejante al del Proyecto europeo CORINE y avanzar hacia la generación de ese tipo de información. En Argentina, en el Congreso Nacional está en tratamiento un proyecto de ley para la protección de humedales que contempla la ejecución de un Inventario Nacional, que podría constituir una base para dicho sistema.

\section{Conclusiones}

Se ha logrado una primera caracterización de los humedales del entorno de la ciudad de Río Grande y la delimitación y cuantificación de sus respectivas superficies, así como la evaluación de su afectación por el crecimiento de la ciudad. El caso de estudio aporta evidencia de la influencia del rápido desarrollo industrial alentado por políticas nacionales sobre la expansión urbana y de la medida en que dicho crecimiento, en condiciones de crisis habitacional, vulnerabilidad social y ocupaciones informales, impactó en los humedales, sobre los cuales se consolidó 1/3 del área urbana. El análisis espacial y temporal realizado demuestra la correspondencia entre pulsos de implementación de políticas de promoción económica con períodos más dinámicos de expansión y de pérdida de zonas húmedas. En el caso de estudio, se constató que las más altas tasas de pérdida se corresponden con estos pulsos, identificándose como factores agravantes la intrusión espontánea de espacios en situación de informalidad, las urgencias del Estado en resolver el déficit habitacional coyuntural y la carencia de un instrumento de ordenamiento del crecimiento urbano. Se constató además que la ocupación de zonas húmedas deprimidas da lugar a altas demandas de áridos para elevar los terrenos y a la proliferación de canteras en playas, vegas y comunidades de estepa. Más de la mitad de los áridos extraídos se destinaron a relleno de dichas zonas, realimentando la pérdida de humedales y generando otras externalidades ambientales.

La metodología desarrollada resultó apropiada para una identificación rápida de humedales desde los aspectos físicos y funcionales, así como para evaluar su afectación por el crecimiento de la ciudad y es aplicable en contextos urbanos costeros con similares limitaciones de información. El estudio espacio-temporal de la expansión urbana y del CCS resultó una herramienta adecuada para el análisis de los efectos de la secuencia: política de promoción industrial - cambio de uso de la tierra para urbanización - pérdida de humedales - expansión urbana y relaciones involucradas. A través de la comparación de la situación observada en Río Grande con otros casos de estudio, pudo verificarse que las diferencias en el manejo del problema en la región con respecto a los países desarrollados, corresponden al mayor nivel de avance de estos últimos en dos aspectos fundamentales: 1) la información de base para el estudio sistemático de la situación de humedales y 2) el reconocimiento institucional de estos ecosistemas en las políticas públicas, a través de su incorporación en la planificación urbana y en la normativa.

Con respecto al primer punto, se recomienda avanzar en la región en el inventario de humedales y en la generación de sistemas de información de usos del suelo.

En relación al segundo punto se considera necesario actualizar los instrumentos de planificación urbana y la normativa relacionada, incorporando la perspectiva de conservación de estos ecosistemas, teniendo en cuenta el contexto de informalidad urbana y la lógica de necesidad de acceso al suelo de los actores sociales. Dado que el área de estudio se corresponde con la de potencial expansión de la ciudad, la identificación y delimitación de humedales obtenida constituye información a considerar para planificar el crecimiento urbano minimizando su pérdida, generando zonas de protección y áreas buffer y armoni- 
zando ambiente y desarrollo bajo prácticas racionales. Los resultados relativos a la afectación de playas evidencian la necesidad de instrumentos para la regulación estricta del manejo de los áridos costeros.

Finalmente, se recomienda promover la valoración de estos ecosistemas mediante programas de educación ambiental dirigidos a diferentes sectores de la comunidad, así como la difusión de los bienes y servicios que proveen los humedales y su fragilidad ante la intervención humana.

\section{Referencias}

Agencia Estatal Boletín Oficial del Estado (1988). Ley 22/1988 de Costas. BOE 181, Madrid. Recuperado de https://www.boe.es/eli/es/1/1988/07/28/22/con

Airoldi, L \& Beck, M. (2007). Loss, status and trends for coastal marine habitats of Europe. En R. Gibson, R. Atkinson \& J. Gordon (Eds), Oceanography and Marine Biology: an annual review, 45, 345-405

Anchorena, J., Collantes, M., Rauber, R., \& Escartín, C. (2009). Humedales de la cuenca del río Grande. Informe Técnico Proyecto: Estrategias de Ordenación de Recursos Hídricos para la Cuenca Binacional del Río Grande. Ushuaia: SDSYA Tierra del Fuego, GEF/PNUMA

Baker, A., Gonzalez, P., Piersma, T., Niles, L., de Lima, I., Atkinson, P., ... \& Aarts, G. (2004). Rapid population decline in red knots: fitness consequences of decreased refuelling rates and late arrival in Delaware Bay. Proceedings of the Royal Society of London. Series B: Biological Sciences, 271(1541), 875-882.https://doi.org/10.1098/rspb.2003.2663

Balfors, B., Mörtberg, U., \& Gontier, M. (2005). Impacts of region-wide urban development on biodiversity in strategic environmental assesment. Journal of environmental assesment, policy and management, 7(2), 229-246. https://doi.org/10.1142/S1464333205002006

Bernal Jaramillo, C. (2006). Estudio preliminar de la degradación física de tres humedales de la sabana de Bogotá y lineamientos ecológicos y paisajísticos para su gestión (Tesis de maestría). Universidad de los Andes, Bogotá. Recuperado de https://repositorio.uniandes.edu.co

Bolund, P., \& Hunhammar, S. (1999). Ecosystem Services in urban areas. Ecological Economics, 29, 293-301. https://doi.org/10.1016/S0921-8009(99)00013-0

Brinson, M. (1993). A Hydrogeomorphic Classification for Wetlands. Wetland Research Program Technical Report WRP-DE-4. Washington DC: US Army Corps of Engineers, Waterways Experiment Station. Recuperado de https://erdc-library.erdc.dren.mil/jspui/bitstream/11681/6483/1/TR-WRP-DE-4.pdf

Brinson, M. (2004). Conceptos y desafíos de la clasificación de humedales. En A. Malvárez y R. F. Bó (Eds.), Documentos del Curso-Taller Bases ecológicas para la clasificación de humedales en Argentina, (pp. 25-36). Bs.As: FCEYN-UBA; RAMSAR; USFWS; USDS. Recuperado de https://lac.wetlands.org/ caso/inventario-de-humedales/

Bujalesky, G. (1997). Morfodinámica y evolución histórica de la espiga Punta Popper y la boca de mareas del río Grande, Tierra del Fuego. Revista de la Asociación Geológica Argentina., 52(2), 187-201.

Bujalesky, G. (2007). Coastal geomorphology and evolution of Tierra del Fuego. Geológica Acta, 5(4), 337-362. http://dx.doi.org/10.1344/105.000000294

Büttner, G., Feranec, J., Jaffrain, G., Mari, L., Maucha, G., \& Soukup, T. (2004). The CORINE land cover 2000 project. EARSeL eProceedings, 3(3), 331-346.

Callaway, J., \& Zedler, J. (2004). Restoration of urban salt marshes: lessons from southern California. Urban Ecosystems, 7, 107-124. Recuperado de https://doi.org/10.1023/B:UECO.0000036268.84546.53.

Cardoso, M.M., \& Fritschy, B. (2012). Revisión de la definición del espacio rururbano y sus criterios de delimitación. Contribución Científica GÆA, 24, 27-39.

Casas, J., Calvache, F., Delgado, S., García-Mayoral, J., Vivas, S., Bayo, M., ...\& Ortega, M. (2003). Inventario abierto de los humedales de la región semiárida almeriense: Consideraciones sobre su tipificación. En M. Paracuellos (Ed.), Ecología, manejo y conservación de los humedales (pp. 171-186). Almería: Inst. Estudios Almerienses.

Clichevsky, N. (2006). Regularizando la informalidad del suelo en América Latina y el Caribe: Una evaluación sobre la base de 13 países y 71 programas. CEPAL, Serie Manuales (50), Santiago de Chile. Recuperado de https://repositorio.cepal.org/handle/11362/5615 
Collantes M., Braun K., Escartín C., Cingolani A., \& Anchorena J. (2005). Patrones de cambio de la vegetación de la estepa fueguina en relación al pastoreo. En M. Oesterheld, M. Aguiar, C. Ghersa, \& J.M. Paruelo (Eds.), La heterogeneidad de la vegetación de los agroecosistemas (pp. 235-251). Facultad de Agronomía, UBA, Buenos Aires. Recuperado de https://www.agro.uba.ar/users/semmarti/papers\%20 pdfs/Oesterheld\%20et\%20al.\%202005.pdf

Collantes, M.B., Anchorena, J.A., Stoffella, S., Escartín, C., \& Rauber, R. (2009). Wetlands of the Magellanic Steppe (Tierra del Fuego, Argentina). Folia Geobotánica, 44(3), 227-245. https://doi.org/10.1007/ s12224-009-9044-y

Cosentino, B., \& Schooley, R. (2018). Dispersal and Wetland Fragmentation. En C. Finlayson, M. Everard, K. Irvine, R. McInnes, B. Middleton, A. van Dam, \& N. Davidson (Eds.), The Wetland Book (pp. 105-111). https://doi.org/10.1007/978-90-481-9659-3

Cowardin, L. M. (1979). Classification of wetlands and deepwater habitats of the United States. Fish and Wildlife Service, US Department of the Interior.

Cowardin, L. M., \& Golet, F. C. (1995). US Fish and Wildlife Service 1979 wetland classification: A review. Classification and inventory of the world's wetlands, 139-152. http://dx.doi.org/10.1007/ $\underline{\mathrm{BF} 00045196}$

Ehrenfeld J. G. (2000). Evaluating wetlands within an urban context. Urban Ecosystems 4, 69-85. https:// doi.org/10.1023/A:1009543920370

Escudero, G., Navedo, J., Piersma, T., De Goeij, P., \& Edelaar, P. (2012). Foraging conditions 'at the end of the world' in the context of long-distance migration and population declines in red knots. Austral Ecology, 37(3), 355-364. https://doi.or/10.1111/j.1442-9993.2011.02283.x

Fank, L. (2019). Promoción Industrial e Informalidad urbana en Tierra del Fuego: análisis histórico comparativo. Revista F@ro, 2(30), 138-162.

Farinha, J., Araújo, P., Silva, E., Carvalho, S., Fonseca, E., \& Lavinas, C. (2005). MedWet Habitat Description System. En Sistema de Classificacão de Habitats Medwet. Instituto da Conservação da Natureza, Centro de Zonas Húmidas, Portuguesel Wetlands Centre, Lisbon, Portugal. pp. 60-104. Recuperado de https://medwet.org/

Federal Geographic Data Committee (2013). Classification of wetlands and deepwater habitats of the United States. FGDC-STD-004-2013. 2nd Edition. Wetlands Subcommittee, Federal Geographic Data Committee and U.S. Fish and Wildlife Service, Washington, DC. Recuperado de https://www.fgdc. gov/standards/projects/wetlands/nwcs-2013

Fink, N., \& Giomi, K. (2019). Extractivismo, bienes comunes y disputas valorativas de actores urbanos en la Patagonia Sur: el conflicto por la extracción de áridos en la reserva Costa Atlántica, Tierra del Fuego. CESLA Int Latin American Studies Review, (23), 111-142.

Gallagher, L., \& Peduzzi, P. (E019). Sand and sustainability: Finding new solutions for environmental governance of global sand resources. United Nations Environmental Programme. Recuperado de http:// hdl.handle.net/20500.11822/28163

Gallardo, M., \& Martínez-Vega, J. (2012). Cambios de usos del suelo en la Comunidad de Madrid: analizando el pasado y simulando el futuro. Tecnologías de la Información Geográfica. Madrid, CSICAGE, 305-314. Recuperado de http://tig.age-geografia.es//2012_Madrid/ponencia2/Gallardo,M_final par.pdf

Gandullo, R., Peña, O., \& Campo, A. (2006). Variación temporal y espacial de parches, corredores y matriz en un humedal ("mallín") del centro-oeste de la provincia de Neuquén. Geograficando, 2(2), $1-21$.

García Ramón, M. D., Tullas Pujol, A., \& Valdovinos Perdices, N. (1995). Geografía rural. Madrid: Síntesis.

Gardner, R. C., Barchiesi, S., Beltrame, C., Finlayson, C., Galewski, T., Harrison, I., ... \& Walpole, M. (2015). State of the world's wetlands and their services to people: a compilation of recent analyses. Ramsar Briefing Note 7. https://doi.org/10.2139/ssrn.2589447

Gobierno de España (2010). Instrucción técnica para la gestión ambiental de las extracciones marinas para la obtención de arena. Ministerio de Medio Ambiente y Medio Rural y Marino. Recuperado de https://www.boe.es/boe/dias/1988/07/29/pdfs/A23386-23401.pdf 
Gobierno de Tierra del Fuego, Antártida e Islas del Atlántico Sur-Poder Judicial (1992). Ley No 32, Ejido Urbano de Río Grande: modificación. Boletín Oficial. Recuperado de http://200.41.191.125:134/ index.php/530-ejido-urbano-de-rio-grande-modificacion.

Guaita, N., López, I., \& Prieto, F. (2008). Cambios de ocupación del suelo en España: implicaciones para la sostenibilidad. Ciudad y Territorio. Estudios Territoriales, 40(156), 235-259. Recuperado de https:// recyt.fecyt.es/index.php/CyTET/article/view/75852

Hooftman, D., Schmid, B., \& Diemer, M. (2004). Genetic Effects of Habitat Fragmentation on Common Species of Swiss Fen Meadows. Conservation Biology, 18(4), 1043-1051. https://doi.org/10.1111/ j.1523-1739.2004.00223.x

Información legislativa del Ministerio de Justicia (1972). Ley 19.640. Régimen especial fiscal y aduanero para el Territorio Nacional de la Tierra del Fuego, Antártida e Islas del Atlántico Sur. Poder Ejecutivo Nacional. Recuperado de http://servicios.infoleg.gob.ar/infolegInternet/anexos/25000-29999/28185/ $\underline{\text { norma.htm }}$

Instituto Nacional de Estadística y Censos (1974). Censo Nacional de Población, Familias y Viviendas 1970. Resultados obtenidos por muestra. INDEC, Buenos Aires.

Instituto Nacional de Estadística y Censos (2010). Censo Nacional de Población, Familias y Viviendas 2010. Jurisdicción: Tierra del Fuego. INDEC, Bs Aires. Recuperado de https://www.indec.gob.ar/ indec/web/Nivel4-CensoProvincia-3-999-94-000-2010

Isla, F., \& Bujalesky, G. (2005). Groundwater dynamics on gravel beaches of Tierra del Fuego, Argentina. J. of Coastal Research, 21(1(211)), 65-72. https://doi.org/10.2112/02102.1

Iturraspe, R., \& Urciuolo, A. (2002). Ciclos deficitarios en el régimen de sistemas lagunares de la estepa fueguina. En J. Bertoni \& C. Dasso (Eds.), XIX Congreso Nacional del Agua. Córdoba, Argentina. UNC (pp. 99-100). Recuperado de https://www.researchgate.net/publication/255785462_Ciclos_ deficitarios_en_el_regimen_de_sistemas_lagunares_de_la_estepa_fueguina.pdf

Iturraspe, R. (2016). Patagonian Peatlands. In C. Finlayson, G. Milton, C. Prentice, \& N. Davidson (Eds.), The Wetland Book II. https://doi.org.10.1007/978-94-007-6173-230-1

Kandus, P., \& Minotti, P. (2018). Propuesta de un marco conceptual y lineamientos metodológicos para el Inventario Nacional de Humedales. Informe final 3iA-UNSAM. Ministerio de Ambiente y Desarrollo Sustentable. Buenos Aires. Recuperado de https://www.argentina.gob.ar/sites/default/files/ inh_propuesta_de_marco_conceptual.pdf

Lanfranchi, G., Cordara, C., Duarte, J., Gimenez, T., Rodriguez, S., \& Ferlicca, F. (2018). ¿Cómo crecen las ciudades argentinas? Estudio de la expansión urbana de los 33 grandes aglomerados. Buenos Aires: CIPPEC. Recuperado de https://www.cippec.org/wp-content/uploads/2018/11/C\%C3\%B3mocrecen-las-ciudades-argentinas-CIPPEC.pdf

Lee S., Dunn, J., Young, R., Connolly, R., Dale, P., Dehayr, R., .. \&, Welsh, D. (2006). Impact of urbanization on coastal wetland structure and function. Austral Ecology, 31, 149-163. https://doi. org.10.1111/j.1442-9993.2006.01581.x

Lin, Q., \& Yu, S. (2018). Losses of natural coastal wetlands by land conversion and ecological degradation in the urbanizing Chinese coast. Scientific reports, 8(1), 1-10. https://doi.org/10.1038/s41598-01833406-X

Lofiego, R., G. Noir, Urciuolo, A., \& Iturraspe, R. (2009). Evaluación hidro-ambiental del estuario del río Grande de Tierra del Fuego. En Bertoni, J. (Coord). Actas XXII Congreso. Nacional del Agua, Trelew, Argentina, 124-133.

Mao, D., Wang, Z., Wu, J., Wu, B., Zeng, Y., Song, K., .. \& Luo, L. (2018). China's wetlands loss to urban expansion. Special Issue Article. Land degradation and development LDD, 29(8), 2644-2657. https://doi. org/10.1002/ldr.2939

Marshall, E. P., \&Shortle,J.S. (2004). Urban development impacts onecosystems. EnJ. Bergstrom, S.J. Goetz, J.S. Shortle (Eds.), Land Use Problems and Conflicts: Causes, Consequences and Solutions (pp. 79-93). https://doi.org/10.4324/9780203799833 
Mirailles Garcia, J., Díaz Aguirre, S., \& Altur Grau, V. (2012). Environmental impact on the Mediterranean Spanish coast produced by the latest process of urban developments. WIT Transactions on Ecology and the Environment, 155, 379-389. https://doi.org/10.2495/SC120321

Moreno-Casasola, P., Aguirre, L., Campos C., Carral, C., Cejudo, E, González-Marín, R., ...\& Vázquez, J. (2019). Humedales costeros de agua dulce y bases para su gobernanza. En E. Rivera-Arriaga, I. Azuz, O. Cervantes, A. Espinoza, R. Silva, A. Ortega,... \& B. Vega (Eds.), Gobernanza y Manejo de las Costas y Mares ante la Incertidumbre. Una guía para tomadores de Decisiones. (pp. 617-648). Universidad Autónoma de Campeche, Ricomar.

Novoa, V., Rojas, O., Ahumada-Rudolph, R., Sáez, K., Fierro, P., \& Rojas, C. (2020). Coastal Wetlands: Ecosystems Affected by Urbanization?. Water, 12(3), 698. https://doi.org/10.3390/w12030698

Pauchard, A., Aguayo, M., Peña, E., \& Urrutia, R. (2006). Multiple effects of urbanization on the biodiversity of developing countries: the case of a fast-growing metropolitan área. Concepción, Chile. Biological Conservation, 127(3), 272-288._https://doi.org/10.1016/j.biocon.2005.05.015

Perillo, G., \& Piccolo C. (2013). Tipos de estuarios y procesos físicos asociados. En J. E. Marcovecchio, R. Freije (Eds.), Procesos Químicos en estuarios (pp. 46-83). Recuperado de http://www.edutecne.utn. edu.ar/proc_quim_estuarios/proc_quim_estuarios.pdf

Pratolongo, P., Piovan, M., Zapperi, G., Negrin, V., González Trilla, G., \& Botté, S. (2013). Humedales en los estuarios. En J. E. Marcovecchio \& R Freije (Eds.), Procesos Químicos en estuarios (pp. 84-108). Buenos Aires: eduTecNe.

Secretaría de la convención de Ramsar. (2013). Manual de la Convención de Ramsar: Guía a la Convención sobre los Humedales, 6a. edición. Recuperado de https://www.ramsar.org/sites/default/files/documents/ library/manual6-2013-sp.pdf

Rojas, C., Munizaga, J., Rojas, O., Martínez, C., \& Pino, J. (2019). Urban development versus wetland loss in a coastal Latin American city: Lessons for sustainable land use planning. Land Use Policy, 80, 47-56. https://doi.org/10.1016/j.landusepol.2018.09.036

Rojas, T., \& Abad, J. D. (2019). Impacts of land use in coastal wetland dynamics. A case of study: Eten's wetland, Peru. E-proceedings of the 38th IAHR World Congress September 1-6, 2019, Panama City, Panama. https://doi.org/10.3850/38WC092019-0204

Scott, D.A., \& Jones, T. (1995). Classification and inventory of wetlands: a global overview. Vegetatio, (118), 3-16. https://doi.org/10.1007/BF00045186

Semeniuk, V., \& Semeniuk, C. (1997). A geomorphic approach to global classification for natural inland wetlands and rationalization of the system used by the Ramsar Convention - a discussion. Wetlands Ecology and Management, 5(2), 145-158. http://dx.doi.org/10.1023/A:1008207726826

Semeniuk, V., \& Semeniuk, C. (2016). Coastal Wetlands. In C. Finlayson, M. Everard, K. Irvine, R. McInnes, B. Middleton, A. van Dam, \& N. Davidson (Eds.), The Wetland Book I (pp. 1-6). http:// dx.doi.org/10.1007/978-94-007-6172-8_330-1

Smith Guerra, P., \& Romero, H. (2009). Efectos del crecimiento urbano del Área Metropolitana de Concepción sobre los humedales de Rocuant-Andalién, Los Batros y Lenga. Revista de Geografía Norte Grande, (43), 81-93. http://dx.doi.org/10.4067/S0718-34022009000200005

Speake, M., Carbone, M., \& Spetter, C. (2020). Análisis del sistema socioecológico del estuario Bahía Blanca (Argentina) y su impacto en los servicios ecosistémicos y el bienestar humano. Investigaciones Geográficas, (73), 121-145. https://doi.org/10.14198/INGEO2020.SCS

Tiner, R. (2017). Wetlands Indicators. A Guide to Wetland Formation, Identification, Delineation, Classification, and Mapping, 2nd Ed. http://dx.doi.org/10.4067/S0718-34022009000200005

Vera, A.G. (2019). La transformación territorial de la ciudad de Río Grande en Tierra del Fuego a partir de las migraciones generadas por decisiones geopolíticas. Area, 25(2), 1-12. Recuperado de https:// area.fadu.uba.ar/area-2502/vera2502/

Viciana Martínez-Lage, A. (1999). Las extracciones de áridos en el litoral de Almería para su utilización en la agricultura intensiva (1956-1997). En A.Viciana Martínez-Lage \& A. Galán Pedregosa (Coord.), Actas de las Jornadas sobre el Litoral de Almería: Caracterización, Ordenación y Gestión de un Espacio Geográfico (pp. 83-110). 